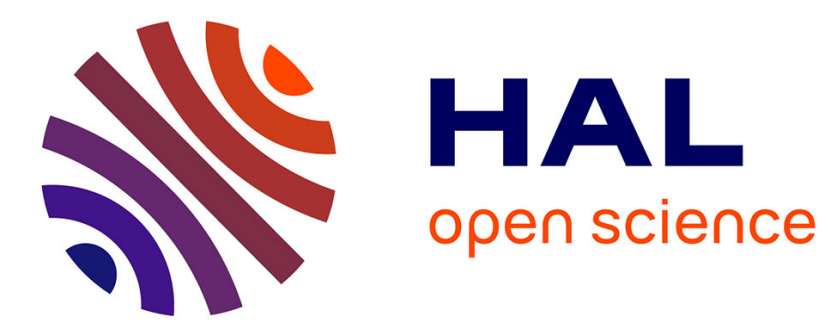

\title{
Soil moisture retrieval over irrigated grassland using X-band SAR data
}

Mohammad El Hajj, N. Baghdadi, Mehrez Zribi, Gilles Belaud, B. Cheviron, Dominique Courault, F. Charron

\section{- To cite this version:}

Mohammad El Hajj, N. Baghdadi, Mehrez Zribi, Gilles Belaud, B. Cheviron, et al.. Soil moisture retrieval over irrigated grassland using X-band SAR data. Remote Sensing of Environment, 2016, 176, pp.202-218. 10.1016/j.rse.2016.01.027 . hal-01336862

\section{HAL Id: hal-01336862 https://hal.science/hal-01336862}

Submitted on 24 Jun 2016

HAL is a multi-disciplinary open access archive for the deposit and dissemination of scientific research documents, whether they are published or not. The documents may come from teaching and research institutions in France or abroad, or from public or private research centers.
L'archive ouverte pluridisciplinaire HAL, est destinée au dépôt et à la diffusion de documents scientifiques de niveau recherche, publiés ou non, émanant des établissements d'enseignement et de recherche français ou étrangers, des laboratoires publics ou privés.

\section{(ㅇ)(1) $\$$}

Distributed under a Creative Commons Attribution - NonCommercial - NoDerivatives| 4.0 
18

El Hajj M., Baghdadi N., Zribi M., Belaud G., Cheviron B., Courault D., and Charron F., 2016. Soil moisture retrieval over irrigated grassland using Xband SAR data. Remote Sensing of Environment, vol. 176, pp. 202-218, doi: http://dx.doi.org/10.1016/j.rse.2016.01.027.

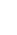

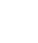

Soil moisture retrieval over irrigated grassland using

$$
\text { X-band SAR data }
$$

\author{
Mohammad El Hajj ${ }^{1}{ }^{*}$, Nicolas Baghdadi ${ }^{1}$, Mehrez Zribi ${ }^{2}$, Gilles Belaud ${ }^{3}$, Bruno \\ Cheviron $^{4}$, Dominique Courault ${ }^{5}$, François Charron ${ }^{3}$
}

2

1 IRSTEA, UMR TETIS, 500 rue François Breton, 34093 Montpellier cedex 5, France

2 CNRS, CESBIO, 18 av. Edouard Belin, bpi 2801, 31401 Toulouse cedex 9, France

3 SupAgro, UMR G-EAU, 2 place Pierre Viala, 34060 Montpellier, France

4 IRSTEA, UMR G-EAU, 361 rue François Breton, 34196 Montpellier cedex 5, France

5 INRA, UMR 1114 EMMAH, Domaine St. Paul, 84914, Avignon, France

19 Abstract: The aim of this study was to develop an inversion approach to estimate surface soil

20 moisture from X-band SAR data over irrigated grassland areas. This approach simulates a

1 coupling scenario between Synthetic Aperture Radar (SAR) and optical images through the

Water Cloud Model (WCM). A time series of SAR (TerraSAR-X and COSMO-SkyMed) and 
23 optical (SPOT 4/5 and LANDSAT 7/8) images were acquired over an irrigated grassland region

24 in southeastern France.

25 An inversion technique based on multi-layer perceptron neural networks (NNs) was used to 26 invert the Water Cloud Model (WCM) for soil moisture estimation. Three inversion 27 configurations based on SAR and optical images were defined: (1) HH polarization, (2) HV 28 polarization, and (3) both $\mathrm{HH}$ and $\mathrm{HV}$ polarizations, all with one vegetation descriptor derived 29 from optical data. The investigated vegetation descriptors were the Normalized Difference 30 Vegetation Index "NDVI", Leaf Area Index "LAI", Fraction of Absorbed Photosynthetically 31 Active Radiation "FAPAR", and the Fractional vegetation COVER "FCOVER". These 32 vegetation descriptors were derived from optical images. For the three inversion configurations, 33 the NNs were trained and validated using a noisy synthetic dataset generated by the WCM for a 34 wide range of soil moisture and vegetation descriptor values. The trained NNs were then 35 validated from a real dataset composed of X-band SAR backscattering coefficients and 36 vegetation descriptor derived from optical images. The use of X-band SAR measurements in $\mathrm{HH}$ 37 polarization (in addition to one vegetation descriptor derived from optical images) yields more 38 precise results on soil moisture $\left(\mathrm{M}_{\mathrm{v}}\right)$ estimates. In the case of NDVI derived from optical images 39 as the vegetation descriptor, the Root Mean Square Error on $\mathrm{M}_{\mathrm{v}}$ estimates was 3.6 Vol.\% for 40 NDVI values between 0.45 and 0.75 , and 6.1 Vol.\% for NDVI between 0.75 and 0.90. Similar 41 results were obtained regardless of the other vegetation descriptor used.

42 Keywords: grassland; TerraSAR-X; COSMO-SkyMED; neural networks; inversion; soil 43 moisture; vegetation indices 


\section{Introduction}

Monitoring the spatio-temporal evolution of soil moisture over irrigated grassland areas is of crucial importance for effective irrigation and crop management (Allen et al., 1998; Brereton and Hope-Cawdery, 1988; Hong et al., 2013; Leenhardt et al., 2004; Merot et al., 2008). In situ sensors to measure soil moisture are costly and provide only local information. Thus, these sensors are not sufficient for monitoring the soil moisture in huge irrigated grassland areas because the soil moisture presents large heterogeneities due to environmental characteristics and irrigation practices. SAR (Synthetic Aperture Radar) data have shown great potential to provide spatially distributed surface soil moisture measurements over bare and vegetated soil (Aubert et al., 2011; Baghdadi et al., 2012a; Gherboudj et al., 2011; Paloscia et al., 2008, 2013; Prevot et al., 1993; Santi et al., 2013). Due to their ability to operate in all weather conditions, SAR sensors offer the opportunity to monitor and quantify the surface soil moisture at a large scale with high spatial and temporal resolution.

SAR remote sensing was widely and primarily used to estimate the soil moisture and surface roughness. Over bare soil (or soil with little vegetation cover) the estimation of soil moisture was performed using either a physical (e.g the Integral Equation Model, Fung et al., 1992) or statistical (e.g Dubois and Oh models, Dubois et al., 1995; Oh, 2004) model in an inversion scheme. In contrast to physical models, statistical models need to be calibrated using in situ measurement and SAR observation acquired over the study area. Moreover, the use of statistical models is limited to the ranges of data variation used for calibration. Most of the studies used radar data in the $\mathrm{X}$ - and $\mathrm{C}$-bands to estimate the soil moisture of bare soil and have shown good results, with an accuracy between 3 and 6 Vol.\% (Aubert et al., 2011; Baghdadi et al., 2012a; Srivastava et al., 2003, 2009; Zribi et al., 2005). 

vegetation canopy not only introduces two-way attenuation in SAR backscatter from soil, but also contributes its own backscatter (He et al., 2014; Srivastava et al., 2011). Most studies used the Water Cloud Model (WCM) in an inversion scheme for soil moisture estimation over areas

71 with vegetated cover. In the WCM the total reflected radar signal is modeled as a function of the 72 vegetation and soil contribution. The vegetation contribution, direct scattering and attenuation, is 73 computed mainly using one biophysical parameter representing the vegetation effect. This 74 biophysical parameter could be estimated from optical data. Therefore, it is important to combine 75 SAR and optical data for operational mapping of soil moisture over areas covered by vegetation 76 (Fieuzal et al., 2011; He et al., 2014; Hosseini and Saradjian, 2011; Notarnicola et al., 2006; 77 Prakash et al., 2012). Currently, the high temporal repetitiveness of X-band (at least one day in 78 case of TSX and CSK) and optical (between 16 and 26 days for Landsat-7/8 and SPOT-4/5 data, 79 respectively) data makes the combined use of SAR and optical data for soil and vegetation 80 parameter monitoring more reliable in near real time.

81 Optical data have shown a great potential to estimate biophysical parameters of vegetation. 82 These parameters can be derived from optical data using physical and statistical models. Physical 83 models (e.g PROSAIL, and SAFY) invert the vegetation spectral reflectance and estimate the 84 biophysical parameters of the vegetation (Botha et al., 2010; Ceccato et al., 2001; Darvishzadeh 85 et al., 2008; Fieuzal et al., 2011). Most statistical models are based on direct relationships 86 between the Normalized Differential Vegetation Index (NDVI) and the measured biophysical 87 parameters of vegetation, such as the LAI of wheat, grasslands, maize, corn and rice (Baret and 88 Guerif, 2006; Baret et al., 2007; Bsaibes et al., 2009; Courault et al., 2008, 2010) 
The possibility of retrieving soil parameters from vegetated surfaces was widely investigated using C-band configurations, whereas few studies were carried out using X-band data. Hajj et al. (2014) showed that the radar signal penetration depth in the $\mathrm{X}$-band (incidence about $30^{\circ}$ ) is high, even in dense grass cover (HVE "Vegetation Height" about 1m, BIO "Biomass" up to 3.9 $\mathrm{kg} / \mathrm{m}^{2}$ ). These results encourage the use of X-band with medium angle (about $30^{\circ}$ ) in both $\mathrm{HH}$ and $\mathrm{HV}$ polarizations for soil moisture estimates over grassland. For C and X-bands SAR data, studies showed that it is possible to estimate the soil moisture with accuracy from 2 to 8 Vol.\% (RMSE "Root Mean Square Error") (Gherboudj et al., 2011; He et al., 2014; Notarnicola et al., 2006; Prévot et al., 1993; Sikdar and Cumming, 2004; Wang et al., 2011; Yang et al., 2012; Yu and Zhao, 2011; Zribi et al., 2011).

The aim of this study is to evaluate the potential of X-band SAR data combined with optical data to estimate soil moisture over irrigated grassland areas located in southeastern France. An approach based on the inversion of the WCM using multi-layer neural networks (NNs) was developed.This approach relies on four main steps: (1) parameterize the WCM, (2) simulate learning the SAR synthetic dataset, (3) train the neural networks according to three inversion configurations using a part of the synthetic dataset, and finally (4) apply the trained NNs on synthetic and real datasets to validate the inversion approach. In this paper, section 2 presents the study areas and the ground-truth measurements performed in situ. Section 3 describes the methodology. The results are shown in section 4. Finally, section 5 presents the principal conclusions. 


\section{Study area and in situ measurements}

\subsection{Study area}

The study area, named "Domaine de Merle", is an experimental farm located in southeastern France (centered at $43.64^{\circ} \mathrm{N}, 5.00^{\circ} \mathrm{E}$ ). Its extent is approximately 400 hectares, among which 150 hectares are irrigated grassland for hay production (Figure 1). The produced hay is highvalue with a Certified Origin Product label (COP) thanks to the specific environmental conditions and conventional irrigation guidelines.

The climate is Mediterranean with a rainy season between September and November. The average cumulative rainfall collected at the study site reached $457.5 \mathrm{~mm}$ in 2013 , and in general varies between $350 \mathrm{~mm}$ and $800 \mathrm{~mm}$ over the past 20 years (Courault et al., 2010). The mean air temperature is approximately $8^{\circ} \mathrm{C}$ and $24^{\circ} \mathrm{C}$ during winter and summer, respectively (Courault et al., 2010). The in situ measured evaporation rate (potential evapotranspiration) can reach 10 $\mathrm{mm}$ /day during the summer due to high temperatures associated with dry and windy conditions. Meteorological instruments installed in the study area allow for recording hourly temperature and precipitation.

The topsoil texture of irrigated plots is stony loam (15\% to $20 \%$ pebbles) with the depth varying from $30 \mathrm{~cm}$ to $80 \mathrm{~cm}$, depending on the plot age (between 10 years and 3 centuries) (Bottraud et al., 1984; Mérot, 2007). The soil is always very smooth thanks to regular irrigation (approximately every 10 days) by gravity. Moreover, the soil has a moderate retention capacity, with concentrated vegetation roots in the upper $30 \mathrm{~cm}$ (Merot et al., 2008).

Plots were leveled with a very gentle slope to allow irrigation by gravity (border irrigation). Irrigation is applied by means of canals which bring water to the highest extremities of the plots. 
131 Each plot is irrigated every 10 days on average from April to September. Plots are harvested 132 three times a year, in May, July, and September.

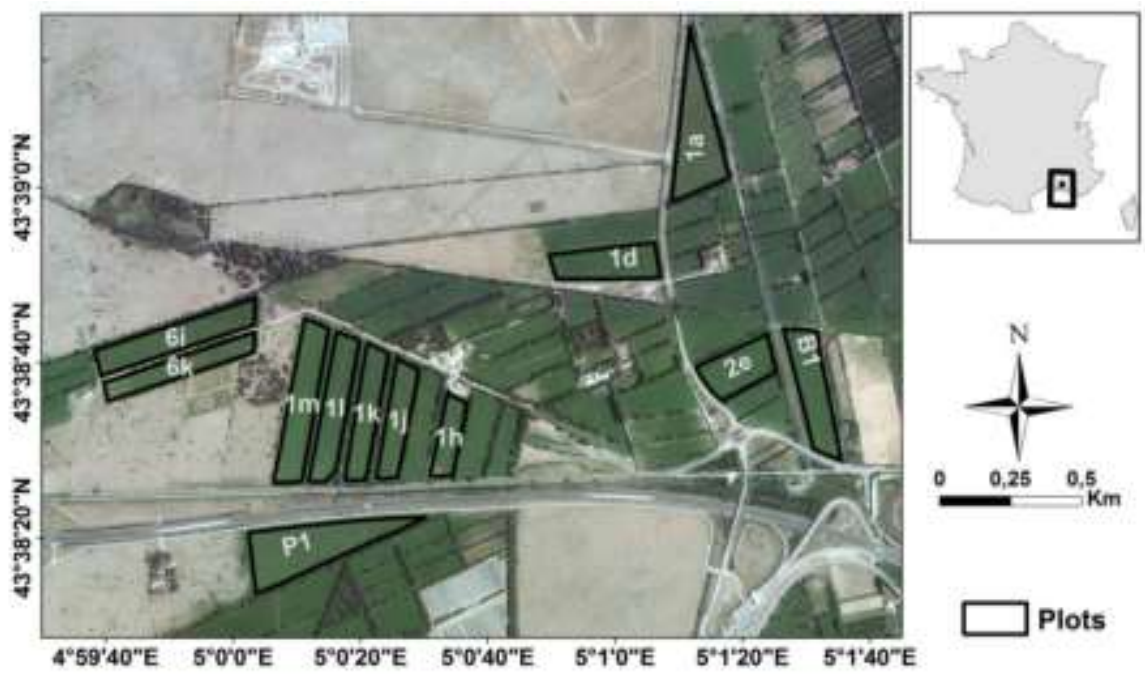

134 Figure 1. Location of the study site (Domaine du Merle). Black polygons delineate training 135 irrigated grassland plots where ground measurements were made.

137 Twenty three X-band SAR images were acquired by the COSMO-SkyMed (CSK) and 138 TerraSAR-X (TSX) sensors between April and October 2013. All SAR images are in dual139 polarization mode ( $\mathrm{HH}$ and $\mathrm{HV}$ ) with incidence angles between $28.3^{\circ}$ and $32.5^{\circ}$ (Table 1 ). 140 Moreover, TSX and CSK images are in Stripmap (pixel spacing of $3 \mathrm{~m}$ ) and Stripmap Pingpong 141 (pixel spacing of $8 \mathrm{~m}$ ) imaging modes, respectively.

142 Radiometric calibration of SAR images was performed using algorithms developed by the 143 German Aerospace Center (DLR) and the Italian Space Agency (ASI). The radiometric 144 calibration transforms the digital number of each pixel $\left(\mathrm{DN}_{\mathrm{i}}\right)$ to a radar backscattering coefficient 
$145\left(\sigma_{\mathrm{i}}{ }^{\circ}\right)$. For the seven TSX MGD (Multi Look Ground Range Detected), the radiometric 146 calibrations were performed according to the following equation (Eineder et al., 2008):

$$
\sigma_{\mathrm{i}}^{\circ}=\mathrm{Ks} \cdot \mathrm{DN}_{\mathrm{i}}^{2} \cdot \sin (\theta)-\mathrm{NESZ} \quad(\mathrm{Eq} .1)
$$

147 where Ks is the calibration constant, $\theta$ is the reference incidence angle, and NESZ is the Noise 148 Equivalent Sigma Zero.

149 For the sixteen CSK images, $\sigma_{\mathrm{i}}^{\circ}$ was computed from the $\mathrm{DN}_{\mathrm{i}}$ using the following equation:

$$
\sigma_{\mathrm{i}}^{\circ}=\mathrm{DN}_{\mathrm{i}}^{2} \cdot \frac{1}{\mathrm{~K} \cdot \mathrm{F}^{2}} \cdot \sin (\theta) \mathrm{R}_{\mathrm{ref}}^{2 \cdot \mathrm{R}}
$$

151 where $R_{\text {ref }}$ is the reference slant range, $R_{\exp }$ is the reference slant range exponent, $K$ is the 152 calibration constant, and $\mathrm{F}$ is the rescaling factor.

Values of parameters given in Equations 1 and 2 are given in the metadata associated with 154 each TSX and CSK image. The $\sigma_{\mathrm{i}}{ }^{\circ}$ were then averaged for each grassland plot and converted to 155 the decibel scale according to the following equation:

$$
\sigma_{\mathrm{dB}}^{\mathrm{o}}=10 \cdot \log _{10}\left(\sum \sigma_{\mathrm{i}}^{\circ}\right) \quad(\mathrm{Eq} .3)
$$

156 The number of looks used to generate a pixel spacing of $3 \mathrm{~m} \mathrm{x} 3 \mathrm{~m}$ is one look in both the 157 range and the azimuth. However, to generate a pixel spacing of $8 \mathrm{~m} \times 8 \mathrm{~m}$, the number of looks 158 is one look in the range and four in the azimuth. The radar image pixel count in the training plots 159 is between 521 and 1686 pixels for the CSK images, and between 3425 and 11320 for the TSX 160 images. 
For training plots, a comparison was performed between the backscattering coefficients (in

162

163

164

165

166

167

168

169

170

171

172

173

174

175

176

177

178

179

180

181

182

183

both $\mathrm{HH}$ and HV polarizations) derived from one TSX and one CSK image, both acquired on the

same day (08/07/2013) with about 40 minutes time interval. For such time interval the soil and vegetation conditions remain unchanged. For both $\mathrm{HH}$ and $\mathrm{HV}$ polarizations, results showed unbiased comparison with low Root Mean Square Error (RMSE 0.4 dB), low Mean Absolute Percentage Error (MAPE $<5 \%)$ and high correlation coefficient $\left(\mathrm{R}^{2} \sim 0.9\right)$.

\subsection{Optical Images}

Thirty optical images were acquired by SPOT-4, SPOT-5, LANDSAT-7 and LANDSAT-8 between April and October 2013 at dates very close to the SAR images (Table 1). The calibration of optical images includes correction for atmospheric effects and ortho-rectification. SPOT-4 images were calibrated by the CESBIO (Centre d'Etudes Spatiales de la BIOsphère) in the framework of the Take 5 experiment (http://www.cesbio.ups-tlse.fr/). Atmospheric correction of SPOT-4 images was performed according to the method described in the study of Hagolle et al. (2008). SPOT-5 and LANDSAT-8 were corrected for atmospheric effects using the Simplified Method of Atmospheric Correction (SMAC) (Rahman and Dedieu, 1994). The SMAC model transforms the TOA reflectance (Top Of Atmosphere) to an atmospherically corrected reflectance. Input data to the SMAC model, the Aerosol Optical Thickness (AOT) at $550 \mathrm{~nm}$, the water vapor content $\left(\mathrm{g} / \mathrm{m}^{2}\right)$, and Ozone, were obtained from the AERONET (AErosol Robotic NETwork) website (http://aeronet.gsfc.nasa.gov/). LANDSAT-7 images, already corrected for atmospheric effects, were downloaded directly from the website of the USGS (http://earthexplorer.usgs.gov/). The atmospheric correction of LANDSAT-7 images were carried out by NASA (National Aeronautics and Space Administration) by applying the 6S (Second Simulation of a Satellite Signal in the Solar Spectrum) radiative transfer model data as 
184 described by Masek et al. (2013). Finally, LANDSAT-7/8 images were already ortho-rectified, 185 whereas SPOT-5 images were ortho-rectified using the terrain correction module implemented in 186 the ERDAS imaging software. The optical image pixel count in the training plots is between 39 187 and 108 for LANDSAT images, and between 79 and 223 for SPOT images.

188 The NDVI was computed from the optical images. Then, NDVI pixel values were averaged 189 for each plot. For all training plots, a comparison was performed between NDVI derived from 190 images acquired by different sensors (LANDSAT-7/8, SPOT-4/5) with time interval less than 191 four days. Results showed unbiased comparison with low RMSE $(\leq 0.04)$, low MAPE $(<5 \%)$, 192 and good correlation coefficient $\left(\mathrm{R}^{2}\right.$ between 0.70 and 0.98$)$. Thus, NDVI derived from different 193 sensors were comparable. 
Table 1. Acquisition dates of SAR and optical images (in 2013). Ground measurements are soil 196 moisture and roughness, LAI, FAPAR, FCOVER, BIO, VWC, and HVE (described in section below).

\begin{tabular}{|c|c|c|c|c|c|c|c|c|c|c|c|c|c|c|c|c|c|c|c|c|c|c|c|c|c|}
\hline & \multicolumn{5}{|c|}{ April } & \multicolumn{5}{|c|}{ May } & \multicolumn{9}{|c|}{ Jun } & \multicolumn{6}{|c|}{ July } \\
\hline & 14 & 17 & 1924 & 25 & 30 & \begin{tabular}{l|l}
03 & 0 \\
\end{tabular} & 411 & 14 & 22 & 27 & \begin{tabular}{l|l}
03 & 04
\end{tabular} & \begin{tabular}{l|l}
4 & 06
\end{tabular} & 10 & 11 & \begin{tabular}{|l|l|}
12 & 13 \\
\end{tabular} & \begin{tabular}{|l|l|}
14 & 1 \\
\end{tabular} & \begin{tabular}{l|l|}
18 & 26
\end{tabular} & \begin{tabular}{|l|l|}
28 & 3 \\
\end{tabular} & 30 & \begin{tabular}{l|l}
05 & 08
\end{tabular} & 12 & \begin{tabular}{l|l}
14 & 16
\end{tabular} & 19 & & \begin{tabular}{l|l|}
29 & 30 \\
\end{tabular} \\
\hline TSX & & & $\mathbf{X}$ & & $\mathbf{X}$ & & & $\mathbf{X}$ & $\mathbf{X}$ & & & & & & & & & & & $\mathbf{X}$ & & & & & $\mathbf{x}$ \\
\hline CSK & & & & & & & & & & & & $\mathbf{X}$ & $\mathbf{X}$ & $\mathbf{X}$ & & $\mathbf{X}$ & $\mathbf{X}$ & & & $\mathbf{X}$ & $\mathbf{X}$ & $\mathbf{X}$ & & & \\
\hline SPOT-4 \& 5 & $\mathbf{X}$ & & $\mathbf{x}$ & & & $\bar{X}$ & & $\mathbf{X}$ & & & & & $\mathbf{X}$ & & $\mathbf{X}$ & & $\mathbf{X}$ & 1 & $\mathbf{x}$ & $\mathbf{X}$ & & & & & \\
\hline $\begin{array}{c}\text { LANDSAT-7 } \\
\text { \& } 8\end{array}$ & & $\mathbf{X}$ & r & $\mathbf{X}$ & & $\mathbf{X}$ & $\mathbf{X}$ & & & $\mathbf{X}$ & $\mathbf{X}$ & & & & $\mathbf{X}$ & & & $\mathbf{X}$ & & & & $\mathbf{X}$ & & $\mathbf{X}$ & $\mathbf{X}$ \\
\hline $\begin{array}{c}\text { In situ } \\
\text { measurement }\end{array}$ & & & $\mathbf{X}$ & & $\mathbf{X}$ & $\mathbf{X}$ & & $\mathbf{X}$ & $\mathbf{X}$ & & $\mathbf{X}$ & $\mathbf{X}$ & $\mathbf{X}$ & $\mathbf{X}$ & & $\mathbf{X}$ & $\mathbf{X}$ & & & $\mathbf{X}$ & $\mathbf{X}$ & $\mathbf{X}$ & $\mathbf{X}$ & & $\mathbf{X} \mid \mathbf{X}$ \\
\hline
\end{tabular}

\begin{tabular}{|c|c|c|c|c|c|c|c|c|c|c|c|c|c|c|c|c|c|c|c|c|c|c|c|}
\hline & \multicolumn{11}{|c|}{ August } & \multicolumn{8}{|c|}{ September } & \multicolumn{4}{|c|}{ October } \\
\hline & 01 & 09 & 13 & 15 & 20 & 21 & 22 & 23 & 26 & 29 & 31 & 02 & 03 & 04 & 10 & 16 & 22 & 24 & 01 & 04 & 06 & 11 & 16 \\
\hline TSX & & & & & & & & & & & & & & & & & & & $\mathbf{X}$ & & & & \\
\hline CSK & $\mathbf{X}$ & $\mathbf{X}$ & & & & & & & $\mathbf{X}$ & $\mathbf{X}$ & & $\mathbf{X}$ & & & $\mathbf{X}$ & & & & & $\mathbf{X}$ & & & $\mathbf{X}$ \\
\hline SPOT-4 \& 5 & $X$ & & & & $\mathbf{X}$ & & & & & & & & & & & & $\mathbf{X}$ & & & & $X$ & $X$ & \\
\hline $\begin{array}{c}\text { LANDSAT-7 \& } \\
8\end{array}$ & & & & $\mathbf{X}$ & & & & $\mathbf{X}$ & & & $\mathbf{X}$ & & & & & $\mathbf{X}$ & & $\mathbf{X}$ & & & & & \\
\hline $\begin{array}{c}\text { In situ } \\
\text { measurement }\end{array}$ & $\mathbf{X}$ & $\mathbf{X}$ & $\mathbf{X}$ & $\mathbf{X}$ & & $\mathbf{X}$ & $\mathbf{X}$ & & $\mathbf{X}$ & $\mathbf{X}$ & & $\mathbf{X}$ & $\mathbf{X}$ & $\mathbf{X}$ & $\mathbf{X}$ & & & & $\mathbf{X}$ & $\mathbf{X}$ & $\mathbf{X}$ & & $\mathbf{X}$ \\
\hline
\end{tabular}

In situ campaigns were conducted simultaneously with SAR acquisitions to collect ground200 truthed measurements of soil and vegetation parameters in twelve training plots (plots 
201 completely flooded or under harvest were not considered). These plots are well levelled and have

202 enough size to be considered as sampling unit (Patel and Srivastava, 2013). The dimension of 203 sampled plot ranges between 2.9 ha and 8.80 ha.

\subsubsection{Soil moisture and roughness}

Due to the high irrigation frequency and evapotranspiration rates, soil moisture measurements were performed close in time (within a window of 2 hours) to the satellite overpass. For each training plot, twenty five to thirty measurements of volumetric soil moisture approximately evenly distributed in space (on average every $20 \mathrm{~m}$ ) were conducted in the top $5 \mathrm{~cm}$ of soil by means of a calibrated TDR (Time Domain Reflectometry) probe. Soil moisture was measured in the top $5 \mathrm{~cm}$ of soil because the radar penetration depth is assumed to be a few centimeters in the

211 X-band (Ulaby et al., 1986). The soil moisture of each plot was represented by the mean of all 212 soil moisture measurements performed in that plot, except when high spatial variability of soil 213 moisture was observed. This variability is the result to current or recent (few hours before) 214 irrigation events. In this case, many homogenous sub-plots were defined using hand-held GPS 215 (brand: GARMIN, model: OREGON 550, location precision $<2 \mathrm{~m}$ ). The soil moisture was 216 approximately 12 Vol.\% when the plot was not supplied by water (irrigation or rainfalls) for 10 217 days during the summer, and it reached approximately 45 Vol.\% approximately 10 hours after 218 irrigation ended. The standard deviation of soil moisture measurements within a plot was 219 between 1 and 5 Vol.\%. 
224 mean square height (Hrms) which represents the vertical scale of roughness, and the correlation

225 length (L), representing the horizontal scale, were derived by processing the roughness profile.

226 The individual autocorrelation functions are averaged, to produce a mean autocorrelation

227 function representing each training plot (exponential function). Then, this mean autocorrelation

228 function was used to derive Hrms and L. The Hrms values varied between 0.35 and $0.55 \mathrm{~cm}$, and

229 the correlation length $(L)$ ranged from 2.00 to $4.60 \mathrm{~cm}$.

\subsubsection{Vegetation parameters}

Additionally, in situ measurement of vegetation parameters were performed to estimate the

232 fresh Biomass (BIO), Vegetation Water Content (VWC), Vegetation Height (HVE), leaf area

233 index (LAI), Fraction of Absorbed Photosynthetically Active Radiation (FAPAR), and Fractional

234 vegetation COVER (FCOVER). The vegetation characteristics within each plot are relatively

235 homogeneous. To determine the BIO, two vegetation samples over a $50 \mathrm{~cm} \times 50 \mathrm{~cm}$ square were

236 clipped using shears at the center of each plot, and then weighed (wet biomass). Later, these

237 samples were dried at $70^{\circ} \mathrm{C}$ for three days to calculate the VWC (VWC = wet biomass - dry

238 biomass). The VWC is well correlated to the $\mathrm{BIO}\left(\mathrm{VWC}=0.80 \mathrm{BIO}, \mathrm{R}^{2}=0.99\right)$, it increases as

239 BIO increases (i.e. growing season progresses). A poor correlation was found between VWC and

240 soil moisture. Twenty measurements of vegetation heights were performed for each plot (the

241 standard deviation of HVE measurements within a plot was between 5 and $10 \mathrm{~cm}$ ). Finally,

242 twenty to thirty hemispherical images were acquired for each plot by means of a fish eye lens.

243 These photos were processed using CanEye software (http://www6.paca.inra.fr/can-eye) to

244 estimate the LAI, FAPAR and FCOVER. Figure 2 showed photos for plots at different

245 vegetation growth stage. For HVE, LAI, FAPAR, and FCOVER the measurements location

246 within each plot were approximately evenly distributed in space (on average every $20 \mathrm{~m}$ ). All 
247 vegetation measurements within each plot were averaged to provide a mean value for each plot.

248 Figure 2 showed photos for plots at different vegetation growth stage.

249 In our study site, HVE reaches a value between $80 \mathrm{~cm}$ and $120 \mathrm{~cm}\left(\mathrm{BIO} \sim 4.2 \mathrm{~kg} / \mathrm{m}^{2}, \mathrm{LAI} \sim 5\right.$ $250 \mathrm{~m}^{2} / \mathrm{m}^{2}$ ) five to seven days before harvest. About ten days after harvest, the HVE reaches a value 251 of about $30 \mathrm{~cm}\left(\mathrm{BIO} \sim 0.80 \mathrm{~kg} / \mathrm{m}^{2}, \mathrm{LAI} \sim 2.5 \mathrm{~m}^{2} / \mathrm{m}^{2}\right)$.

\begin{tabular}{|c|c|}
\hline 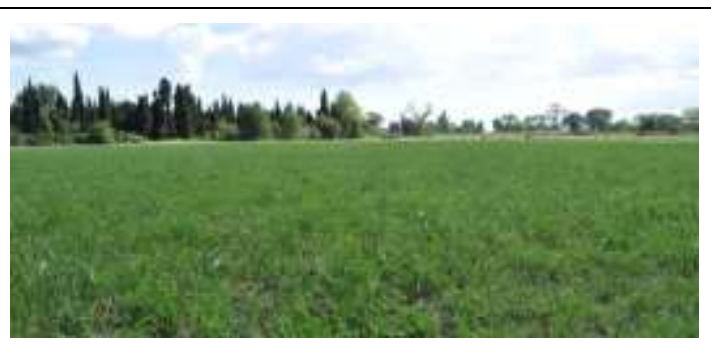 & $\begin{array}{l}\text { Training plot 2e (Jun 10, 2013) } \\
\mathrm{BIO}=0.89 \mathrm{~kg} / \mathrm{m}^{2} \\
\mathrm{HVE}=0.25 \mathrm{~m} \\
\mathrm{LAI}=1.01 \mathrm{~m}^{2} / \mathrm{m}^{2}\end{array}$ \\
\hline & $\begin{array}{l}\text { Training plot } 11 \text { (April 19, 2013) } \\
\mathrm{BIO}=1.90 \mathrm{~kg} / \mathrm{m}^{2} \\
\mathrm{HVE}=0.50 \mathrm{~cm} \\
\mathrm{LAI}=3.98 \mathrm{~m}^{2} / \mathrm{m}^{2}\end{array}$ \\
\hline & $\begin{array}{l}\text { Training plot } 1 \mathrm{~m} \text { (May 14, 2013) } \\
\mathrm{BIO}=3.56 \mathrm{~kg} / \mathrm{m}^{2} \\
\mathrm{HVE}=1.13 \mathrm{~m} \\
\mathrm{LAI}=4.71 \mathrm{~m}^{2} / \mathrm{m}^{2}\end{array}$ \\
\hline
\end{tabular}

253 Figure 2. Ground-based photographs of study sites illustrating variations in grass growth stages along with in situ measurements. 
The in situ campaigns, frequently performed along each of the three growth cycles, capture 257 full range of soil moisture and vegetation conditions (Table 2). Table 2 shows the number of 258 sampled plots that correspond to soil and vegetation conditions.

259 Table 2: The number of sampled plots for each soil moisture and vegetation conditions

\begin{tabular}{|c|c|c|c|}
\hline & $\begin{array}{c}\text { Low } \\
(\mathrm{HVE} \leq 25 \mathrm{~cm})\end{array}$ & $\begin{array}{c}\text { Medium } \\
(25<\mathrm{HVE} \leq 60 \mathrm{~cm})\end{array}$ & $\begin{array}{c}\text { High } \\
(\mathrm{HVE}>60 \mathrm{~cm})\end{array}$ \\
\hline $\begin{array}{c}\text { Low } \\
\left(\mathrm{M}_{\mathrm{v}} \leq 20 \text { Vol. } \%\right)\end{array}$ & 10 & 17 & 13 \\
\hline $\begin{array}{c}\text { Medium } \\
\left(20<\mathrm{M}_{\mathrm{v}} \leq 30 \text { Vol. } \%\right)\end{array}$ & 19 & 40 & 20 \\
\hline \multirow[t]{2}{*}{$\begin{array}{c}\text { High } \\
\left(\mathrm{M}_{\mathrm{v}}>30 \text { Vol. } \%\right)\end{array}$} & 20 & 21 & 18 \\
\hline & $\begin{array}{c}\text { Low } \\
\left(\mathrm{VWC} \leq 0.7 \mathrm{~kg} / \mathrm{m}^{2}\right)\end{array}$ & $\begin{array}{c}\text { Medium } \\
\left(0.7<\mathrm{VWC} \leq 1.3 \mathrm{~kg} / \mathrm{m}^{2}\right)\end{array}$ & $\begin{array}{c}\text { High } \\
\left(\mathrm{VWC}>1.3 \mathrm{~kg} / \mathrm{m}^{2}\right)\end{array}$ \\
\hline $\begin{array}{c}\text { Low } \\
\left(\mathrm{M}_{\mathrm{v}} \leq 20 \text { Vol. } \%\right)\end{array}$ & 12 & 13 & 15 \\
\hline $\begin{array}{c}\text { Medium } \\
\left(20<\mathrm{M}_{\mathrm{v}} \leq 30 \text { Vol. } \%\right)\end{array}$ & 30 & 26 & 23 \\
\hline $\begin{array}{c}\text { High } \\
\left(\mathrm{M}_{\mathrm{v}}>30 \mathrm{Vol} . \%\right)\end{array}$ & 20 & 22 & 17 \\
\hline
\end{tabular}

260

261

\section{Methods}

\subsection{Radar signal modeling}

In this study, the Water Cloud model (WCM), developed by Attema and Ulaby (1978), was used for modeling the total backscattered radar signal according to soil moisture and vegetation

265 parameters. This semi-empirical model is widely used over soil with vegetation cover because it 266 can be easily performed in an inversion scheme to estimate soil moisture and vegetation 267 parameters (Gherboudj et al., 2011; Prevot et al., 1993; De Roo et al., 2001; Sikdar and 268 Cumming, 2004; Soon-Koo Kweon et al., 2012; Wang et al., 2011; Yang et al., 2012; Yu and 269 Zhao, 2011; Zribi et al., 2011). The significant variables in the WCM are the medium height and 
270 dielectric cylinder density (Attema and Ulaby, 1978). The latter was assumed to be proportional

271 to the volumetric water content of the canopy. Very few studies have compared different

272 vegetation parameters to define the optimal one for use in the WCM. Champion (1991) and

273 Champion and Guyot (1991) found that the LAI $\left(\mathrm{m}^{2} / \mathrm{m}^{2}\right)$ better represents the wheat canopy in

274 the WCM than the VWC per unit volume $\left(\mathrm{kg} / \mathrm{m}^{3}\right)$. Said et al. (2012) compared the use of LAI

$275\left(\mathrm{~m}^{2} / \mathrm{m}^{2}\right)$, VWC $\left(\mathrm{kg} / \mathrm{m}^{2}\right)$, and HVE and found that the use of LAI as the vegetation descriptor

276 allows the accurate simulation of the vegetation volume contribution (sugarcane, cherry, rice,

277 and grassland).

278 In this context, the WCM represents the total backscattered radar signal $\left(\sigma_{\text {tot }}^{0}\right)$ in linear scale

279 as a sum of the direct vegetation contribution $\left(\sigma^{0}{ }_{\text {veg }}\right)$ and soil contribution attenuated by the 280 vegetation volume $\left(\mathrm{T}^{2} \sigma^{0}{ }_{\text {sol }}\right)$.

$$
\begin{gathered}
\sigma_{\text {tot }}^{0}=\sigma_{\text {veg }}^{0}+T^{2} \sigma_{\text {sol }}^{0} \\
\sigma_{\text {veg }}^{0}=A \cdot V_{1} \cdot \cos \theta\left(1-T^{2}\right) \\
T^{2}=\operatorname{Exp}\left(-2 \cdot B \cdot V_{2} \cdot \sec \theta\right) \\
\sigma_{\text {sol }}^{0}=C(\theta) \exp \left(D \cdot M_{v}\right)
\end{gathered}
$$


Where:

- $\mathrm{V}_{1}$ and $\mathrm{V}_{2}$ are vegetation descriptors (BIO $\left(\mathrm{kg} / \mathrm{m}^{2}\right)$, VWC $\left(\mathrm{kg} / \mathrm{m}^{2}\right), \mathrm{HVE}(\mathrm{m}), \mathrm{LAI}$ $\left(\mathrm{m}^{2} / \mathrm{m}^{2}\right)$, FAPAR, FCOVER, and NDVI)

- $\theta$ is the radar incidence angle

- $\mathrm{A}$ and $\mathrm{B}$ are parameters that depend on the canopy descriptors and radar configurations

- $\mathrm{T}^{2}$ is the two way attenuation

- $\mathrm{C}$ is dependent on the roughness and incidence angle

- $\mathrm{D}$ is the sensitivity of the radar signal to volumetric soil moisture in the case of bare soils, which is dependent on radar configurations

- $\mathrm{M}_{\mathrm{v}}$ is the volumetric soil moisture (expressed in Vol.\%).

\subsection{Soil moisture retrieval}

In this study, soil moisture was estimated by means of multi-layer perceptron neural networks (NNs). The Levenberg-Marquardt optimization algorithm (Marquardt, 1963) was used to train the NNs. The NNs architecture is composed of three layers: input, one hidden, and output. The NNs have a two dimensional input vector when using one polarization (HH or HV) in addition to one vegetation descriptor. Using two polarizations ( $\mathrm{HH}$ and $\mathrm{HV}$ ) in addition to one vegetation descriptor, the NNs have a three dimensional input vector. The one dimensional output vector contains soil moisture. The numbers of neurons associated with the hidden layer was determined by training the NNs using different numbers of neurons. 20 hidden neurons provided accurate estimates of reference parameters (Baghdadi et al., 2012a; Chai et al., 2009). Sigmoidal and linear transfer functions were associated with the hidden and output layer, respectively. These 
functions allow non-linear transformations from input to output (Del Frate and Solimini, 2004; Del Frate et al., 2003; Paloscia et al., 2008). To study the performance of the inversion approach, the NNs were trained and validated on the synthetic datasets.

\section{A Synthetic dataset of SAR backscatter data was generated from the parameterized WCM to} be used in the procedures leading to the estimation of soil moisture by means of the neural networks (NNs) technique. The parameterized WCM is able to simulate the backscattering coefficients at both $\mathrm{HH}$ and $\mathrm{HV}$ polarizations using the volumetric soil moisture, one vegetation descriptor, and incidence angle values as input variables. Only parameters easily estimated from optical images such as NDVI, LAI, FAPAR and FCOVER were considered in the synthetic datasets generation. Indeed, only few studies showed that the optical data could be used for estimating the biomass, vegetation water content, and the vegetation height. Four synthetic datasets have thus been generated using NDVI, LAI, FAPAR and FCOVER as vegetation descriptors (V1 and V2 in equations 4 and 5) to evaluate the most adequate vegetation descriptor for vegetation layer characterization in the WCM, and to open a perspective for future works based on SAR and optical data coupling. Indeed, several studies have developed methods to correct atmospheric effects in optical images, allowing the accurate estimation of the NDVI (Agapiou et al., 2011; Masek et al., 2013; Rahman and Dedieu, 1994; Saastamoinen, 1972; Vermote et al., 2002). Regarding the other vegetation descriptors, many studies have developed methods to estimate LAI, FAPAR, and FCOVER from optical images (Baret and Guyot, 1991; Bsaibes et al., 2009; Carlson and Ripley, 1997; Carlson et al., 1994; Claverie et al., 2013; Courault et al., 2008; Darvishzadeh et al., 2008b; Duveiller et al., 2011; Fensholt et al., 2004; Guerschman et al., 2009; Li et al., 2014; North, 2002). In addition, in the framework of our study, LAI, FAPAR, and FCOVER of our studied grassland were derived from optical images 

Neural NETwork) tool developed based on algorithms proposed by Baret et al. (2007) and then optimized through the SIRRIMED project (http://www.sirrimed.org/index.php). A comparison was performed between the LAI, FAPAR and FCOVER derived from BV-NNET (using optical images) and those derived from hemispherical photos. Results showed unbiased estimations of LAI, FAPAR, and FCOVER by the BV-NNET. Moreover, the BV-NNET estimates the LAI with an RMSE of $0.66 \mathrm{~m}^{2} / \mathrm{m}^{2}$ and an RRMSE (as well as MAPE) around 29\%. For FAPAR and FCOVER, an RMSE around 0.13 and an RRMSE (as well as MAPE) around 19\% were obtained.

The synthetic dataset based on NDVI as the vegetation descriptor comprises 80 elements $(8 \mathrm{x}$ 10, Table 3). Each element of the dataset contains radar signals in $\mathrm{HH}$ and $\mathrm{HV}$ polarizations for a 339 given NDVI and volumetric soil moisture (Table 3). Moreover, synthetic dataset based on LAI 340 and FAPAR (as well as FCOVER) comprised 248 (8 x 31, table 3) and 168 (8 $\times 21$, table 3) 341 elements, respectively.

Table 3. The minimum, maximum, and step values of WCM inputs.

\begin{tabular}{|c|c|c|c|c|}
\hline Parameter & Min value & Max value & Step & Total elements \\
\hline NDVI & 0.45 & 0.90 & 0.05 & 10 \\
\hline LAI $\left(\mathbf{m}^{\mathbf{2}} / \mathbf{m}^{\mathbf{2}}\right)$ & 0.0001 & 6 & 0.20 & 31 \\
\hline FAPAR & 0.0001 & 1 & 0.05 & 21 \\
\hline FCOVER & 0.0001 & 1 & 0.05 & 21 \\
\hline M $_{\mathbf{v}}($ Vol.\%) & 10 & 45 & 5 & 8 \\
\hline
\end{tabular}


To make WCM simulations more realistic, uncertainties of SAR measurements were added to the simulated radar response. The uncertainties range is between 0.6 and $1 \mathrm{~dB}$ for CSK and TSX sensors (Agenzia Spaziale Italiana, 2007; Coletta et al., 2007; Iorio et al., 2010; Schwerdt et al., 346 2008; Torre et al., 2011). Thus, we considered two absolute uncertainties values ( \pm 0.75 , and $347 \pm 1.00 \mathrm{~dB}$ ) to be added to the simulated radar response. Moreover, relative uncertainties were 348 added on our reference vegetation descriptor values (NDVI, LAI, FAPAR, and FCOVER) to 349 handle the associated uncertainty. For NDVI, Simoniello et al. (2004) reported a relative 350 uncertainty of approximately $8 \%$ on NDVI values estimated from AVHRR (Advanced Very 351 High Resolution Radiometer) calibrated data over pasture and cultivated areas. El Hajj et al. 352 (2008) found that the relative uncertainty on NDVI computed from SPOT-5 surface reflectance 353 data over sugarcane fields is approximately 13\%. For the other vegetation descriptors, studies 354 showed for crop canopies (corn, grass, sunflower, maize, wheat, rapeseed and sunflower) relative 355 uncertainty between $10 \%$ and $30 \%$ for LAI, and between $5 \%$ and $20 \%$ for FAPAR and FCOVER 356 (Bsaibes et al., 2009; Claverie et al., 2013; Courault et al., 2008; Duveiller et al., 2011; North, 357 2002). In addition, the uncertainty on the vegetation descriptor estimates depends on crop type 358 (Bsaibes et al., 2009; Claverie et al., 2013). Moreover, the comparison between derived LAI, 359 FAPAR, and FCOVER from our optical images with ground-truthed measurements yields a 360 relative RMSE (Root Mean Square Error) of 29.12, 19.24, and 18.14\%, respectively. Therefore, 361 in our study we considered a relative additive noise of 15,30 , and $20 \%$ on the NDVI, LAI, and 362 FAPAR (as well as FCOVER), respectively.

363 Zero-mean Gaussian noise with a standard deviation equal to absolute and relative 364 uncertainties were added to the radar signal simulated by the WCM and reference vegetation 365 descriptors, respectively. Finally, to obtain statistically significant datasets, 500 random 
samplings of zero-mean Gaussian noise was added to each simulated radar response and each vegetation descriptor value.

Three case studies to estimate soil moisture using X-band SAR data were evaluated:

- Case 1: Noisy radar signal at HH polarization and noisy vegetation descriptor as the inputs to NNs, and soil moisture as the target.

- Case 2: Noisy radar signal at HV polarization and noisy vegetation descriptor as the inputs to NNs, and soil moisture as the target.

- Case 3: Noisy radar signal at HH and HV polarizations and noisy vegetation descriptor as the inputs to NNs, and soil moisture as the target.

Finally, the calibrated NNs were used to invert real SAR measurements for estimation of the soil moisture. The inversion was performed according to the configurations above, but using SAR and a vegetation descriptor (LAI, FAPAR, and FCOVER) derived from optical images instead of the noisy radar signal and vegetation descriptors.

\section{Results and discussions}

\subsection{Water Cloud Model parameterization, and modelling results}

This section presents the results of the Water Cloud Model (WCM) parameterization, and shows the radar signal modelling results as a function of soil and vegetation parameters.

\subsubsection{Water Cloud Model parameterization}

The real dataset composed of SAR data and measurements of soil moisture and vegetation descriptors was divided into two sub-datasets. The first sub-dataset (training dataset) was used to fit the WCM model, whereas the second (validation dataset) was used to validate the soil 
moisture estimation of the WCM model. The training dataset contains the SAR and the groundtruthed data obtained during the three cycles for the half of training plots, whereas the validation dataset comprises the data collected for other half of plots. These two real sub-datasets contain a wide range of soil moisture $\left(\mathrm{M}_{\mathrm{v}}\right)$ and vegetation descriptor values measured in situ $(\mathrm{BIO}, \mathrm{VWC}$, FCOVER) (Table 4). The two real sub-datasets have almost the same ranges of variation.

Table 4: ranges of variation of real training and validation datasets

\begin{tabular}{|c|c|c|c|c|c|}
\hline \multirow{12}{*}{ 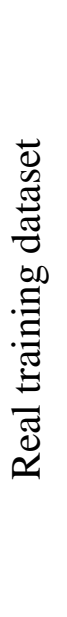 } & & Min & Mean & MAX & Unit \\
\hline & $\mathrm{Mv}$ & 10.9 & 25.6 & 39.0 & Vol.\% \\
\hline & In situ BIO & 0.28 & 1.41 & 4.14 & $\mathrm{Kg} / \mathrm{m}^{2}$ \\
\hline & In situ VWC & 0.15 & 1.12 & 3.35 & $\mathrm{Kg} / \mathrm{m}^{2}$ \\
\hline & In situ HVE & 0.08 & 0.48 & 1.20 & $\mathrm{~m}$ \\
\hline & In situ LAI & 0.10 & 2.64 & 5.88 & $\mathrm{~m}^{2} / \mathrm{m}^{2}$ \\
\hline & In situ FAPAR & 0.20 & 0.79 & 1.00 & - \\
\hline & In situ FCOVER & 0.12 & 0.63 & 0.96 & - \\
\hline & LAI (BV-NNET) & 0.20 & 2.63 & 5.04 & $\mathrm{~m}^{2} / \mathrm{m}^{2}$ \\
\hline & FAPAR (BV-NNET) & 0.16 & 0.77 & 0.98 & - \\
\hline & FCOVER (BV-NNET) & 0.16 & 0.66 & 0.96 & - \\
\hline & NDVI & 0.47 & 0.73 & 0.88 & - \\
\hline \multirow{11}{*}{ 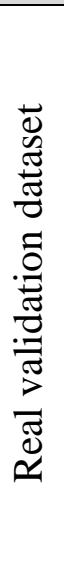 } & $\mathrm{Mv}$ & 14.1 & 27.0 & 47.0 & Vol.\% \\
\hline & In situ BIO & 0.30 & 1.31 & 3.46 & $\mathrm{Kg} / \mathrm{m}^{2}$ \\
\hline & In situ VWC & 0.03 & 1.02 & 2.87 & $\mathrm{Kg} / \mathrm{m}^{2}$ \\
\hline & In situ HVE & 0.08 & 0.45 & 1.15 & $\mathrm{~m}$ \\
\hline & In situ LAI & 0.26 & 2.23 & 4.00 & $\mathrm{~m}^{2} / \mathrm{m}^{2}$ \\
\hline & In situ FAPAR & 0.20 & 0.73 & 0.93 & - \\
\hline & In situ FCOVER & 0.09 & 0.57 & 0.88 & - \\
\hline & LAI (BV-NNET) & 0.26 & 2.16 & 5.10 & $\mathrm{~m}^{2} / \mathrm{m}^{2}$ \\
\hline & FAPAR (BV-NNET) & 0.09 & 0.69 & 0.98 & - \\
\hline & FCOVER (BV-NNET) & 0.09 & 0.58 & 0.94 & - \\
\hline & NDVI & 0.48 & 0.69 & 0.87 & - \\
\hline
\end{tabular}


WCM parameterization consists of first estimating the sensitivity parameter D before fitting

396

397

398

399

400

401

402

403

404

405

406

407

408

409

410

411

412

413

414

415

416

417

the model against ground-truthed measurements to estimate parameters A, B, and C (equations 4, 5, and 6).

- To estimate parameter D, SAR backscattering coefficients in $\mathrm{HH}$ and $\mathrm{HV}$ polarizations (dB scale) were linearly related to soil moisture (Vol.\%) for 18 plots recently harvested (vegetation very short), to have the minimum vegetation effect on the backscattering coefficients (Figure 3). The slopes of these linear regressions represent the sensitivity of the backscattered radar signal to volumetric soil moisture on the $\mathrm{dB}$ scale (Figure 3). Results showed a good correlation between radar signal and volumetric soil moisture $\left(\mathrm{R}^{2}=0.87\right.$ and 0.71 for $\mathrm{HH}$ and $\mathrm{HV}$, respectively). Moreover, results showed that the $\mathrm{HH}$ polarization is slightly more sensitive $(0.172$ $\mathrm{dB} / \mathrm{Vol} . \%)$ to volumetric soil moisture rather than $\mathrm{HV}(0.135 \mathrm{~dB} / \mathrm{Vol} . \%)$ polarization (Figure 3). In the WCM model, the sensitivity parameter D is represented on a linear scale. In linear unit, these sensitivities $\mathrm{D}_{\mathrm{HH}}$ and $\mathrm{D}_{\mathrm{HV}}$ are $0.03971\left[\mathrm{~m}^{2} / \mathrm{m}^{2}\right] /[\mathrm{Vol} . \%]$ and $0.03116\left[\mathrm{~m}^{2} / \mathrm{m}^{2}\right] /[\mathrm{Vol} . \%]$ for $\mathrm{HH}$ and HV polarizations, respectively

- $\mathrm{A}, \mathrm{B}$ and $\mathrm{C}$ parameters were then estimated for each radar polarization and each vegetation descriptor (NDVI and ground-truthed BIO, VWC, HVE, LAI, FAPAR, and FCOVER) by minimizing the sum of squares of the differences between the simulated and measured radar signal. Therefore, the WCM was parameterized according to seven vegetation descriptors (Table 5). With A, B and C parameters, it becomes possible to predict WCM components $\left(\sigma^{0}{ }_{\text {veg }}, \mathrm{T}^{2}\right.$, and $\left.\sigma_{\text {sol }}^{0}\right)$ and consequently the total backscattering coefficient $\left(\sigma_{\text {tot }}^{0}\right)$ using one vegetation descriptor and the soil moisture values as inputs in the WCM. 


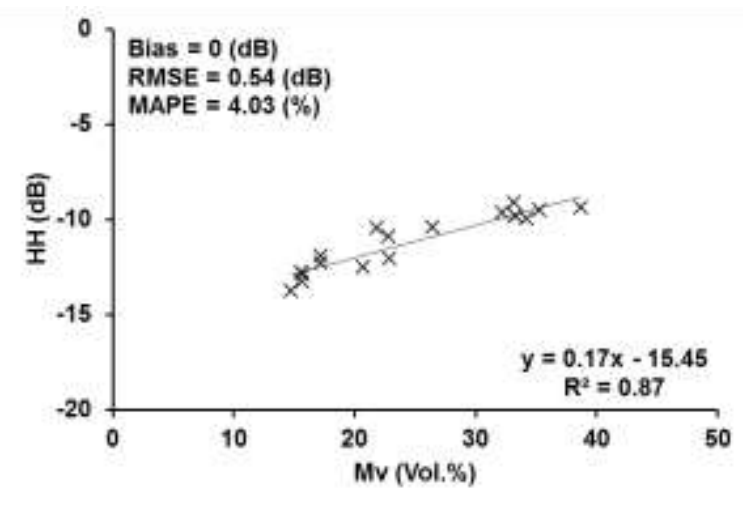

(a)

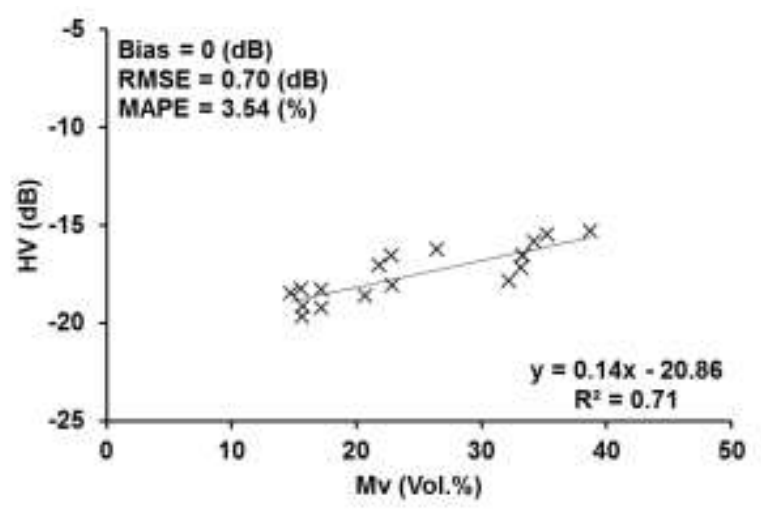

(b)
418 419

420

421

422

423 backscattering coefficients of the real validation dataset. Results showed that the fit of the WCM

Figure 3. Sensitivity of radar signal in both $\mathrm{HH}$ and HV polarization to volumetric soil moisture. was slightly better in $\mathrm{HH}$ polarization than in $\mathrm{HV}$ polarization (Table 5). The limited correlation quality of the fit is approximately the same for all the used vegetation descriptors with the RMSE

428 (Root Mean Square Error) on the predicted backscattering coefficients between 0.76 and $0.86 \mathrm{~dB}$ 429 in $\mathrm{HH}$, and between 0.85 and $0.94 \mathrm{~dB}$ in $\mathrm{HV}$ polarization, depending on the used vegetation descriptor. Water cloud model is considered adequately fitted because the RMSE on simulated radar signal in both $\mathrm{HH}$ and $\mathrm{HV}$ polarizations is less than $1 \mathrm{~dB}$, which is the same magnitude as the CSK and TSX sensors precision (Agenzia Spaziale Italiana, 2007; Coletta et al., 2007; Iorio et al., 2010; Schwerdt et al., 2008; Torre et al., 2011). Several studies used the WCM model to coefficient $\left(\mathrm{R}^{2}\right)$ is not due to difficulty of model to simulate radar data but particularly to limited range of radar data dynamic for different moisture and vegetation conditions. In addition, the predict radar backscattering coefficients (Attema and Ulaby, 1978; Gherboudj et al., 2011; 
435 Prevot et al., 1993; Ulaby et al., 1984). Attema and Ulaby, (1978) simulated the X-band 436 backscattering coefficients for crops fields (alfalfa, corn, milo, and wheat) in $\mathrm{HH}$ and VV 437 polarizations for a wide range of incidence angles $\left(0^{\circ}-70^{\circ}\right)$ with a RMSE of simulated 438 backscattering coefficients ranging between 1.5 and $2 \mathrm{~dB}$, depending on the crop type. Ulaby et $439 a l$, (1984) simulated the radar backscattering coefficients in the X-band (VV polarization and $50^{\circ}$ 440 incidence angle) for wheat fields with a RMSE of 1.6 dB. Prevot et al. (1993) obtained a RMSE 441 for wheat fields on the simulated backscattering coefficients of 1.24 and $0.72 \mathrm{~dB}$ in the C-band $442\left(\mathrm{HH}, 20^{\circ}\right)$ and X-band $\left(\mathrm{VV}, 40^{\circ}\right)$, respectively. Gherboudj et al. (2012) predicted the 443 backscattering coefficients in the C-band, in quad-polarization mode with a $30^{\circ}$ incidence angle 444 for wheat and pea fields. The RMSE on the predicted backscattering coefficients in $\mathrm{HH}$ and VV 445 polarizations was approximately 1 (for wheat) and $0.7 \mathrm{~dB}$ (for peas), respectively. In cross 446 polarization, the backscattering coefficient was simulated with a RMSE of 1.2 and $0.2 \mathrm{~dB}$ for 447 wheat and pea fields, respectively. 
Table 5. Fit of WCM parameters for $\mathrm{HH}$ and $\mathrm{HV}$ polarizations (real validation dataset).

\begin{tabular}{|c|c|c|c|c|c|c|c|c|c|c|}
\hline $\mathrm{V} 1=\mathrm{V} 2$ & $\mathbf{A}_{\mathrm{HH}}$ & $\mathbf{B}_{\mathrm{HH}}$ & $\mathrm{C}_{\mathrm{HH}}$ & $\mathbf{D}_{\mathrm{HH}}$ & $\mathbf{A}_{\mathrm{HV}}$ & $\mathbf{B}_{\mathrm{HV}}$ & $\mathrm{C}_{\mathrm{HV}}$ & $\mathbf{D}_{\mathrm{HV}}$ & $\begin{array}{c}\mathbf{R}^{2}{ }_{H H} \\
\left(\mathbf{R}_{H V}^{2}\right)\end{array}$ & $\begin{array}{c}\operatorname{RMSE}_{\mathrm{HH}} \\
\left(\mathrm{RMSE}_{\mathrm{HV}}\right) \\
(\mathbf{d B})\end{array}$ \\
\hline $\begin{array}{c}\text { Ground- } \\
\text { truthed } \\
\text { BIO }\end{array}$ & 0.0345 & 0.0995 & 0.0334 & 0.03971 & 0.0068 & 0.1850 & 0.0093 & 0.03116 & $\begin{array}{c}0.49 \\
(0.39)\end{array}$ & $\begin{array}{c}0.85 \\
(0.86)\end{array}$ \\
\hline $\begin{array}{l}\text { Ground- } \\
\text { truthed } \\
\text { VWC }\end{array}$ & 0.0438 & 0.1047 & 0.0324 & 0.039711 & 0.0084 & 0.1927 & 0.0088 & 0.03116 & $\begin{array}{c}0.49 \\
(0.39)\end{array}$ & $\begin{array}{c}0.86 \\
(0.86)\end{array}$ \\
\hline $\begin{array}{c}\text { Ground- } \\
\text { truthed } \\
\text { HVE }\end{array}$ & 0.1045 & 0.4314 & 0.0357 & 0.03971 & 0.0207 & 0.7882 & 0.0105 & 0.03116 & $\begin{array}{c}0.52 \\
(0.40)\end{array}$ & $\begin{array}{c}0.79 \\
(0.85)\end{array}$ \\
\hline $\begin{array}{c}\text { Ground- } \\
\text { truthed } \\
\text { LAI }\end{array}$ & 0.0205 & 0.0613 & 0.0338 & 0.03971 & 0.0041 & 0.0856 & 0.0088 & 0.03116 & $\begin{array}{c}0.48 \\
(0.29)\end{array}$ & $\begin{array}{c}0.86 \\
(0.95)\end{array}$ \\
\hline $\begin{array}{l}\text { Ground- } \\
\text { truthed } \\
\text { FAPAR }\end{array}$ & 0.0911 & 0.3275 & 0.0354 & 0.03971 & 0.0177 & 0.4662 & 0.0096 & 0.03116 & $\begin{array}{c}0.47 \\
(0.25)\end{array}$ & $\begin{array}{c}0.80 \\
(0.93)\end{array}$ \\
\hline $\begin{array}{l}\text { Ground- } \\
\text { truthed } \\
\text { FCOVER }\end{array}$ & 0.1021 & 0.3696 & 0.0355 & 0.03971 & 0.0203 & 0.5212 & 0.0095 & 0.03116 & $\begin{array}{c}0.48 \\
(0.27)\end{array}$ & $\begin{array}{c}0.82 \\
(0.94)\end{array}$ \\
\hline NDVI & 0.0767 & 0.7944 & 0.0644 & 0.03971 & 0.016474 & 1.134 & 0.0221 & 0.03116 & $\begin{array}{c}0.51 \\
(0.33)\end{array}$ & $\begin{array}{c}0.76 \\
(0.93)\end{array}$ \\
\hline
\end{tabular}

450

451

\subsubsection{Modelling results}

452 Modelling results obtained by using the NDVI as the vegetation descriptor in the WCM

453 model will be presented first because (i) the best fit of water cloud model was obtained with

454 NDVI as vegetation descriptor, and (ii) it is easier to derive NDVI from optical data than LAI,

455 FAPAR, and FCOVER. Next, results with the LAI, FAPAR, FCOVER, BIO, VWC, and HVE as

456 vegetation descriptors will be briefly discussed. 
The WCM components $\left(\mathrm{T}^{2} \sigma^{\circ}\right.$ sol and $\left.\sigma^{\circ}{ }_{\text {veg }}\right)$ were simulated for wide ranges of soil moisture $458\left(\mathrm{M}_{\mathrm{v}}\right)$ and NDVI values using the WCM with the NDVI as the vegetation descriptor. For both HH 459 and $\mathrm{HV}$ polarizations, the vegetation contribution $\left(\sigma^{\circ}{ }_{\text {veg }}\right)$, soil contribution $\left(\sigma^{\circ}\right.$ sol $)$, two-way 460 attenuation $\left(\mathrm{T}^{2}\right)$, and consequently, the total backscattered signal $\left(\sigma^{\circ}\right.$ tot $)$ were generated in a linear 461 scale using the parameterized equations (3) to (6). NDVI values ranging from 0.45 to 0.90 were 462 used to simulate the vegetation contribution and the two-way attenuation (V1=V2=NDVI in 463 equations 4 and 5). In addition, the soil contribution was simulated using $\mathrm{M}_{\mathrm{v}}$-values ranging from 46410 to $45 \mathrm{Vol} \%$ (equation 6). The maximum values of NDVI and $\mathrm{M}_{\mathrm{v}}$ correspond to the highest 465 values derived from optical images and measured in situ, respectively.

466 Figure 4 shows the modelled $\sigma^{\circ}{ }_{\text {veg }}, \mathrm{T}^{2} \sigma^{\circ}{ }_{\text {sol }}$ and $\sigma^{\circ}$ tot in $\mathrm{dB}$ units as a function of $\mathrm{M}_{\mathrm{v}}$ using 467 different values of $\operatorname{NDVI}(0.5,0.7$, and 0.9$)$. In addition, the modelled $\sigma^{\circ}{ }_{\text {veg }}, \mathrm{T}^{2} \sigma^{\circ}$ sol and $\sigma^{\circ}$ tot 468 were also plotted according to NDVI for $\mathrm{M}_{\mathrm{v}}$ values of 15, 20, 30 and 40 Vol.\% (Figure 5).

469 Figure 4 shows that $\sigma^{\circ}$ tot in both $\mathrm{HH}$ and $\mathrm{HV}$ polarizations are always sensitive to soil 470 moisture even for high NDVI values. The sensitivity of $\sigma_{\text {tot }}^{\circ}$ to soil moisture decreases with the 471 NDVI for NDVI between 0.45 and 0.90 . For NDVI value equal to 0.50 this sensitivity is about $4720.14 \mathrm{~dB} / \%$ and $0.10 \mathrm{~dB} / \%$ for $\mathrm{HH}$ and $\mathrm{HV}$, respectively. Moreover, for a NDVI value equal to 4730.9 , this sensitivity is approximately 0.08 and $0.04 \mathrm{~dB} / \mathrm{Vol} \%$ in $\mathrm{HH}$ and $\mathrm{HV}$, respectively. For 474 each case in figure 4 statistical index were provided in table 6. Results showed that the WCM 475 adequately simulates SAR real validation dataset observations $(0<$ Bias $<0.3$, RMSE $<1 \mathrm{~dB}$, 476 RRMSE and MAPE $<7 \%)$.

477 Figure 5 shows that $\sigma^{\circ}$ tot in both $\mathrm{HH}$ and $\mathrm{HV}$ polarization is slightly sensitive to the NDVI (for 478 NDVI between 0.45 and 0.90). Indeed, as the vegetation grows, the decreasing soil contribution 479 is similar to the increasing vegetation contribution. $\sigma^{\circ}$ tot shows slight decreases with increases in 
480 the NDVI until reaching a minimum, and starts to slightly increase. In both $\mathrm{HH}$ and $\mathrm{HV}$ 481 polarizations, $\sigma_{\text {tot }}^{\circ}$ decreases with NDVI for a NDVI lower than $0.60,0.75$, and 0.90 for $\mathrm{M}_{\mathrm{v}}$ of 48215,20 , and $30 \mathrm{Vol} \%$, respectively. However, the $\sigma_{\text {to }}^{\circ}$ in both $\mathrm{HH}$ and $\mathrm{HV}$ polarizations always 483 decreases with NDVI (NDVI between 0.45 and 0.90) for $\mathrm{M}_{\mathrm{V}}$ equal to $40 \mathrm{Vol} \%$ due to the high 484 soil contribution (Figures $5 \mathrm{~d}$ and $\mathrm{h}$ ). This decrease of ${\sigma^{\circ}}_{\text {tot }}$ with the NDVI is related to an 485 increase in the attenuation of the soil contribution $\left(\mathrm{T}^{2}\right)$, which is more important than the 486 enhanced contribution from the vegetation canopy (Balenzano et al., 2011; Brown et al., 2003;

487 Mattia et al., 2003). Beyond these values of NDVI thresholds, $\sigma^{\circ}$ tot increases slightly with NDVI 488 for $\mathrm{M}_{\mathrm{v}}$ values between 15 and $30 \mathrm{Vol} . \%$. This increase of $\sigma^{\circ}$ tot with NDVI results in the increase 489 of the vegetation contribution combined with the decrease in the soil contribution. Moreover, the 490 decrease and increase of $\sigma^{\circ}$ tot according to the NDVI are slightly more pronounced in $\mathrm{HV}$ than in $491 \mathrm{HH}$ polarization. Regarding vegetation contribution $\left(\sigma^{\circ}{ }_{\text {veg }}\right)$, results showed that the modelled $492 \sigma_{\text {veg }}^{\circ}$ in $\mathrm{HH}$ polarization increases from $-17.7 \mathrm{~dB}$ for NDVI of 0.45 to $-13.2 \mathrm{~dB}$ for NDVI of 0.90.

493 For HV polarization, $\sigma^{\circ}{ }_{\text {veg }}$ increases from $-23.5 \mathrm{~dB}$ to $-18.8 \mathrm{~dB}$ for NDVI between 0.45 and 0.90 .

494 For each case in figure 5, statistical index were provided in table 7. Results showed that the 495 WCM adequately simulates SAR real validation dataset observations $(0<$ Bias $<0.7$, RMSE $\leq$ $4961 \mathrm{~dB}, \mathrm{RRMSE}$ and MAPE $<8 \%)$. 


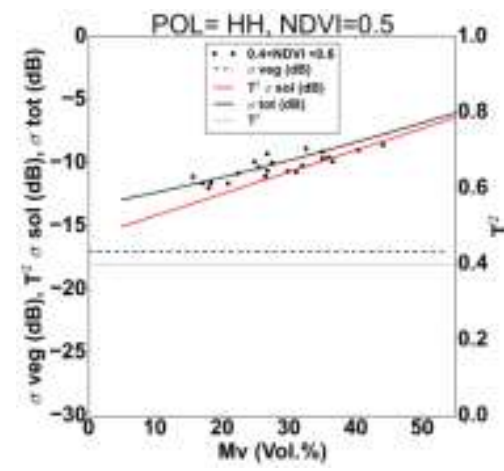

(a)

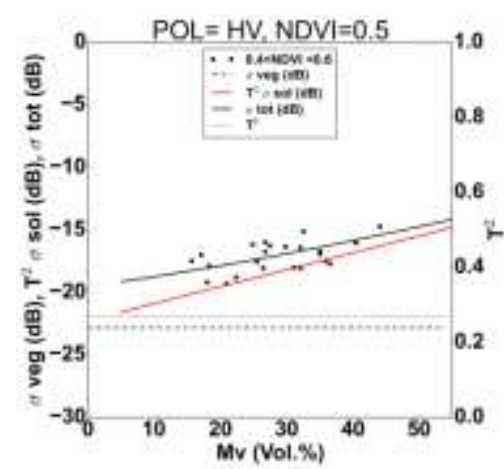

(d)

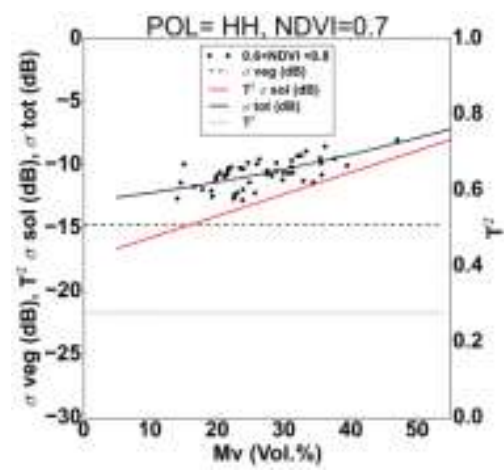

(b)

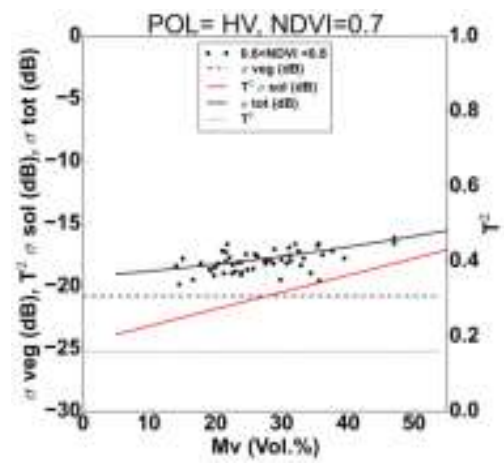

(e)

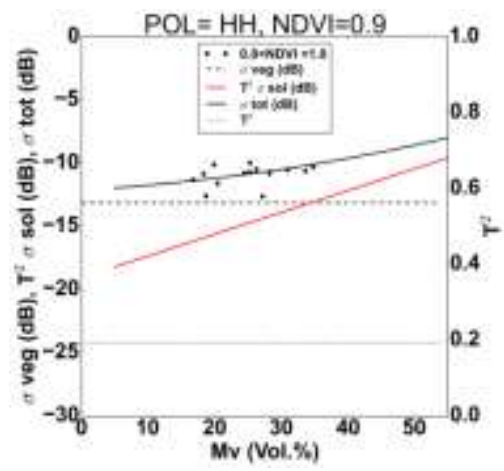

(c)

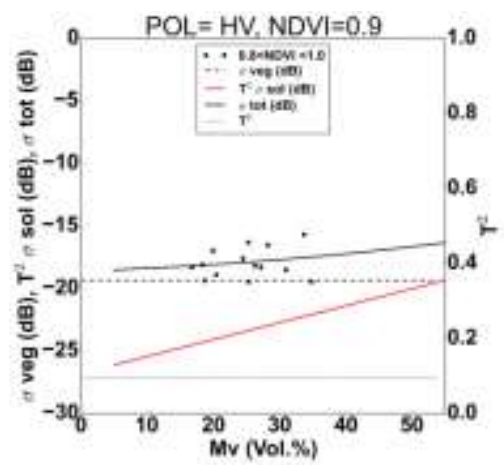

(f)
Figure 4. Behavior of WCM components $\left(\sigma^{\circ}{ }_{\text {veg }}, \mathrm{T}^{2} \sigma^{\circ}{ }_{\text {sol }}\right.$, and $\left.\sigma^{\circ}{ }_{\text {tot }}\right)$ in both $\mathrm{HH}$ and $\mathrm{HV}$ polarizations according to $M_{v}$. Black points represent the SAR data ( $\sigma_{\text {tot }}^{\circ}$ : real validation dataset) associated with NDVI measurements within \pm 0.1 of the NDVI used in the modelling.

Table 6: Statistical index for each case in figure 4

\begin{tabular}{|c|c|c|c|c|c|c|c|c|}
\hline Case & Polarization & NDVI & Bias $(\mathrm{dB})$ & RMSE $(\mathrm{dB})$ & RRMSE $(\mathrm{dB})$ & MAPE $(\mathrm{dB})$ & $\mathrm{R}^{2}$ & $\mathrm{Nb}$ \\
\hline Figure 4a & $\mathrm{HH}$ & 0.50 & 0.3 & 0.6 & 6.0 & 5.4 & 0.71 & 23 \\
\hline Figure 4b & $\mathrm{HH}$ & 0.70 & 0.0 & 0.9 & 8.0 & 6.7 & 0.45 & 52 \\
\hline Figure 4c & $\mathrm{HH}$ & 0.90 & 0.1 & 0.8 & 7.0 & 4.8 & 0.12 & 14 \\
\hline \multicolumn{7}{|l|}{} \\
\hline Figure 4d & $\mathrm{HV}$ & 0.50 & 0.1 & 1.0 & 5.7 & 5.1 & 0.30 & 23 \\
\hline Figure 4e & $\mathrm{HV}$ & 0.70 & 0.2 & 0.8 & 4.3 & 3.3 & 0.26 & 52 \\
\hline Figure 4f & $\mathrm{HV}$ & 0.90 & 0.1 & 1.1 & 6.4 & 5.5 & 0.03 & 14 \\
\hline
\end{tabular}




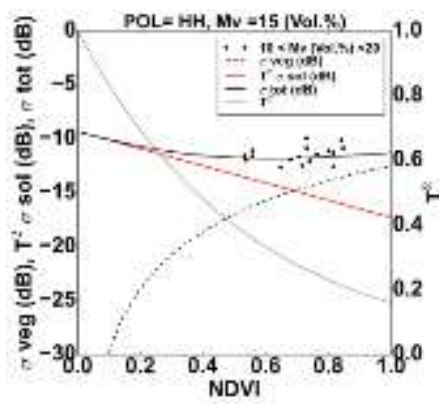

(a)

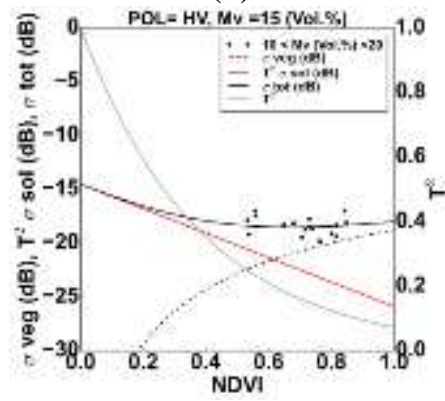

(e)

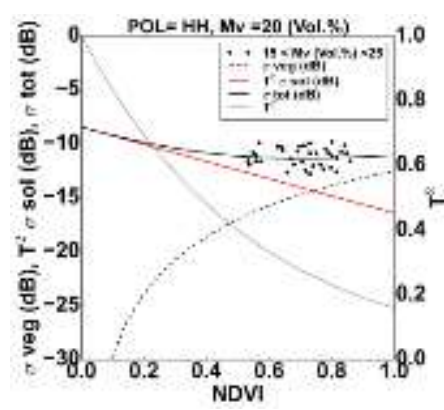

(b)

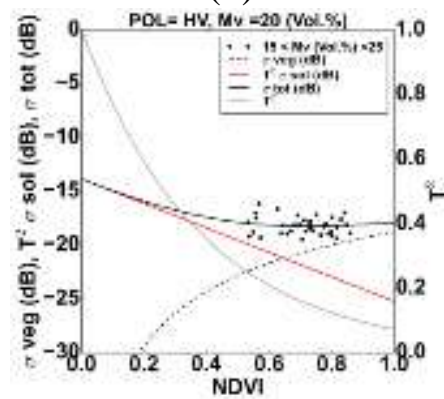

(f)

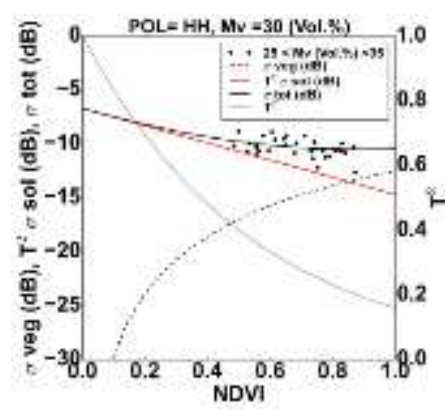

(c)

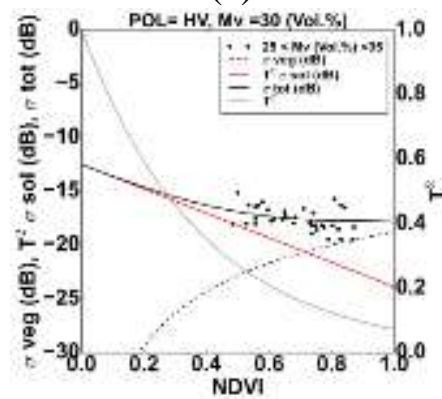

(g)

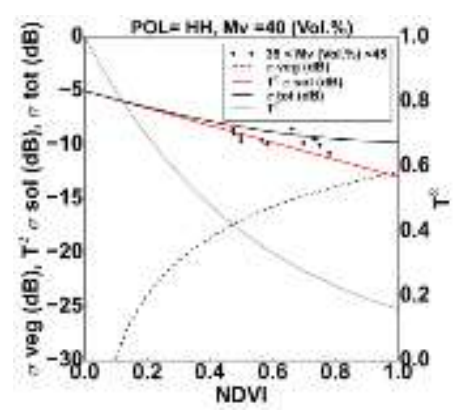

(d)

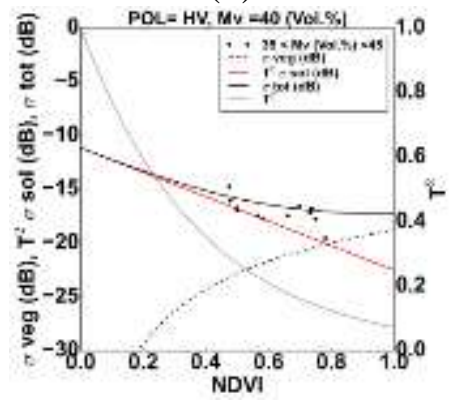

(h)

503 Figure 5. Behavior of WCM components $\left(\sigma^{\circ}{ }_{\text {veg, }} \mathrm{T}^{2} \sigma^{\circ}{ }_{\text {sol }}\right.$, and $\left.\sigma_{\text {tot }}^{\circ}\right)$ in both $\mathrm{HH}$ and $\mathrm{HV}$

504 polarizations according to NDVI. Black points represent the SAR data $\left(\sigma^{\circ}\right.$ tot: real validation

505 dataset) associated with $\mathrm{M}_{\mathrm{v}}$ measurements within \pm 5 vol. $\%$ of the $\mathrm{M}_{\mathrm{v}}$ used in the modelling.

Table 7: Statistical index for each case in figure 5

\begin{tabular}{|c|c|c|c|c|c|c|c|c|}
\hline Case & $\begin{array}{c}\text { Polarizatio } \\
\mathrm{n}\end{array}$ & $\begin{array}{c}\mathrm{M}_{\mathrm{V}} \\
(\mathrm{Vol} \%)\end{array}$ & $\begin{array}{c}\text { Bias } \\
(\mathrm{dB})\end{array}$ & $\begin{array}{c}\text { RMSE } \\
(\mathrm{dB})\end{array}$ & $\begin{array}{c}\text { RRMSE } \\
(\%)\end{array}$ & $\begin{array}{c}\text { MAPE } \\
(\%)\end{array}$ & $\mathrm{R}^{2}$ & $\mathrm{Nb}$ \\
\hline Figure 5a & $\mathrm{HH}$ & 15 & -0.3 & 0.8 & 6.8 & 5.6 & 0.13 & 17 \\
\hline Figure 5b & $\mathrm{HH}$ & 20 & -0.1 & 0.9 & 7.7 & 6.7 & 0.00 & 36 \\
\hline Figure 5c & $\mathrm{HH}$ & 30 & 0.1 & 0.7 & 7.1 & 5.4 & 0.16 & 37 \\
\hline Figure 5d & $\mathrm{HH}$ & 40 & 0.6 & 0.8 & 8.7 & 7.6 & 0.32 & 12 \\
\hline \multicolumn{7}{|l|}{} \\
\hline Figure 5e & $\mathrm{HV}$ & 15 & -0.1 & 0.8 & 4.3 & 3.6 & 0.05 & 17 \\
\hline Figure 5f & $\mathrm{HV}$ & 20 & 0.0 & 0.8 & 4.5 & 3.7 & 0.01 & 36 \\
\hline Figure 5g & $\mathrm{HV}$ & 30 & 0.1 & 1.0 & 5.5 & 4.7 & 0.18 & 37 \\
\hline Figure 5h & $\mathrm{HV}$ & 40 & 0.6 & 1.1 & 6.3 & 5.0 & 0.41 & 12 \\
\hline
\end{tabular}

507 Table 8 shows NDVI thresholds from which the $\mathrm{T}^{2} \sigma^{\circ}{ }_{\text {sol }}$ is dominated by $\sigma^{\circ}{ }_{\text {veg }}\left(\mathrm{T}^{2} \sigma^{\circ}{ }_{\text {sol }}<\sigma^{\circ}{ }_{\text {veg }}\right)$.

508 In $\mathrm{HH}$ polarization, these thresholds are approximately $0.69,0.74,0.85,0.97$ for soil moisture of 
15, 20, 30 and 40 Vol.\%, respectively. In HV polarizations and for $\mathrm{M}_{\mathrm{v}}$ values of 15, 20, 30 and

$51040 \mathrm{Vol} \%, \sigma^{\circ}{ }_{\text {veg }}$ dominates $\mathrm{T}^{2} \sigma^{\circ}{ }_{\text {sol }}$ for NDVI values greater than $0.62,0.65,0.71$, and 0.79 ,

511 respectively. Thus, for a given soil moisture value, the thresholds of NDVI for which the

512 vegetation contribution dominates the soil contribution are lower in HV than in HH (Table 8).

513 Table 8. Threshold values of vegetation descriptors at which $\sigma^{\circ}{ }_{\text {veg }}$ dominates $\mathrm{T}^{2} \sigma^{\circ}{ }_{\text {sol }}$ at both $\mathrm{HH}$

514 and HV polarizations. Dash symbols mean that the $\sigma^{\circ}{ }_{\text {veg }}$ is always dominated by $\mathrm{T}^{2} \sigma^{\circ}$ sol.

\begin{tabular}{|c|c|c|c|c|c|c|c|c|}
\hline \multirow[b]{2}{*}{$M_{v}($ Vol.\%) } & \multicolumn{4}{|c|}{ HH polarization } & \multicolumn{4}{|c|}{ HV polarization } \\
\hline & 15 & 20 & 30 & 40 & 15 & 20 & 30 & 40 \\
\hline NDVI & 0.69 & 0.74 & 0.85 & 0.97 & 0.62 & 0.65 & 0.71 & 0.79 \\
\hline $\mathbf{L A I}\left(\mathbf{m}^{2} / \mathbf{m}^{2}\right)$ & 4.22 & 4.60 & 5.43 & - & 3.69 & 3.94 & 4.47 & 5.05 \\
\hline FAPAR & 0.87 & 0.95 & - & - & 0.77 & 0.82 & 0.93 & - \\
\hline FCOVER & 0.78 & 0.84 & 0.99 & - & 0.68 & 0.72 & 0.82 & 0.92 \\
\hline BIO $\left(\mathrm{kg} / \mathrm{m}^{2}\right)$ & 2.55 & 2.77 & 3.28 & 3.85 & 1.95 & 2.07 & 2.34 & 2.64 \\
\hline $\operatorname{VWC}\left(\mathrm{kg} / \mathrm{m}^{2}\right)$ & 2.20 & 2.40 & 2.84 & 3.35 & 1.70 & 1.82 & 2.06 & 2.32 \\
\hline HVE (m) & 0.70 & 0.76 & 0.90 & - & 0.55 & 0.58 & 0.65 & 0.73 \\
\hline
\end{tabular}

515 WCM components were also modelled using the LAI, FAPAR, FCOVER, BIO, VWC and

516 HVE as vegetation descriptors. Similar results on the behavior of modelled total backscattered

517 radar signal $\left(\sigma_{\text {tot }}^{\circ}\right)$ were obtained with all vegetation descriptors. Table 8 shows the values of the

518 vegetation descriptors at which $\sigma^{\circ}{ }_{\text {veg }}$ dominates $\mathrm{T}^{2} \sigma^{\circ}$ sol. As an example, for soil moisture of 20

519 Vol. $\%, \sigma^{\circ}{ }_{\text {veg }}$ in $\mathrm{HH}$ polarization dominates $\mathrm{T}^{2} \sigma^{\circ}$ sol for LAI values higher than $4.60 \mathrm{~m}^{2} / \mathrm{m}^{2}$. In

520 addition, for some soil moisture and vegetation descriptor conditions, the vegetation contribution

521 is always dominated by the soil contribution (dash symbol in Table 8). As an example, for soil 
522 moisture of $40 \mathrm{Vol} \%$, the vegetation contribution in $\mathrm{HH}$ polarization is always dominated by the

523 soil contribution for HVE values between 0 and $1.2 \mathrm{~m}$ (maximum value of HVE obtained by

524 ground-truthed measurements and used in modelling). In addition, Table 8 shows that the

525 vegetation contribution in HV polarization dominates the soil contribution at threshold values of 526 vegetation descriptors which are lower than those observed in $\mathrm{HH}$ polarization.

528 Synthetic and real datasets were used to estimate the soil moisture for the three inversion 529 configurations defined in section 3.2: (1) using the radar signal in $\mathrm{HH}$ and one vegetation 530 descriptor, (2) using the radar signal in HV and one vegetation descriptor, and (3) using the radar 531 signal in both $\mathrm{HH}$ and $\mathrm{HV}$ and one vegetation descriptor. The estimated soil moistures were 532 compared to reference soil moisture values to evaluate the accuracy of the soil moisture 533 estimates of each inversion configuration.

534 Before the use of neural networks for soil moisture estimation, the WCM model was 535 numerically inverted. For some points of the synthetic and real datasets where the SAR 536 backscattering coefficient is lower than the vegetation contribution simulated by the WCM, the 537 direct inversion of the WCM is not numerically possible (about $10 \%$ of the datasets). Such 538 limitation is overcome when using the NNs for both synthetic and real datasets. In addition, the 539 Root Mean Square Error on $\mathrm{M}_{\mathrm{v}}$ estimates was better with the NNs than using the direct inversion 540 of the WCM (precision on $\mathrm{M}_{\mathrm{v}}$ two times better). For these reasons, the neural networks inversion 541 technique for soil moisture estimation was considered. 
To estimate the soil moisture, neural networks were built for each inversion configuration using a part of the synthetic dataset. The quality of inversion approaches were studied using both the other part of the synthetic dataset and the real validation dataset.

\subsubsection{Synthetic dataset}

The synthetic dataset was composed of $2.10^{7}$ elements (10 NDVI values x $8 \mathrm{M}_{\mathrm{v}}$ values x 500 random sampling values of the NDVI x 500 random sampling values of the simulated radar signal). According to the radiometric accuracy of the TerraSAR-X and COSMO-SkyMed signals, the radar signal simulated by the WCM model was noised using an additive Gaussian noise with zero mean and a standard deviation of 0.75 and $1 \mathrm{~dB}$. The synthetic dataset was randomly divided into $80 \%$ training and $20 \%$ validation data samples. The prediction error based on a 5-fold cross-validation was estimated for each inversion configuration to assess the performance of the neural networks. Analysis of the results obtained with NDVI as the vegetation descriptor will be provided in detail whereas the results based on LAI, FAPAR, and FCOVER as the vegetation descriptors will be briefly described.

\section{The Root Mean Square Error (RMSE), the Relative Root Mean Square Error (RRMSE), the} Mean Absolute Percentage Error (MAPE), the associated mean deviation (bias $=$ estimated $\mathrm{M}_{\mathrm{v}}$ reference $\mathrm{M}_{\mathrm{v}}$ ), and the correlation coefficient $\left(\mathrm{R}^{2}\right)$ were used to evaluate the performance of each inversion configuration. Table 9 presents statistical indexes (RMSE, RRMSE, MAPE, bias, and $R^{2}$ ) on $M_{v}$ estimates computed from the validation dataset for reference $M_{v}$ between 10 and 45 Vol.\% and NDVI values between 0.45 and 0.90. Table 9 shows that the RMSE (as well as RRMSE, and MAPE) on $\mathrm{M}_{\mathrm{v}}$ estimates is lower with $\mathrm{HH}$ polarization than with $\mathrm{HV}$ polarization (configuration 1 in comparison to configuration 2, Table 9). For a noise condition on the radar signal of $\pm 0.75 \mathrm{~dB}$, the RMSE is $4.5 \mathrm{Vol} \%$ (RRMSE and MAPE about $17 \%$ ) with $\mathrm{HH}$ 


\begin{tabular}{|c|c|c|}
\hline & $\begin{array}{l}\text { Noise on } \sigma_{\text {tot }}^{0}: \\
\quad \pm 0.75 \mathrm{~dB}\end{array}$ & $\begin{array}{l}\text { Noise on } \sigma_{\text {tot: }}^{0}: \\
\quad \pm 1.00 \mathrm{~dB}\end{array}$ \\
\hline Configuration 1 (HH and NDVI) & $4.5|16.5| 17.1|0.0| 0.85$ & $5.5|19.8| 21.0|0.0| 0.78$ \\
\hline Configuration 2 (HV and NDVI) & $5.1|18.5| 19.2|0.0| 0.81$ & $5.7|20.7| 21.8|0.0| 0.77$ \\
\hline Configuration 3 (HH, HV and NDVI) & $3.7|13.6| 13.7|0.0| 0.90$ & $4.5|16.2| 16.7|0.0| 0.85$ \\
\hline
\end{tabular}

Figure 6 illustrates the RMSE evolution of $M_{v}$ estimates as a function of NDVI for values between 0.45 and 0.90 for each inversion configuration. For each value of NDVI, statistics were 580

compared to 5.1 Vol.\% (RRMSE and MAPE $19 \%$ ) with HV. In addition, results showed that the use of both $\mathrm{HH}$ and HV (in addition to the NDVI, configuration 3) slightly decreases the RMSE on $\mathrm{M}_{\mathrm{v}}$ estimates (lower than $1 \mathrm{Vol} \%$ ). With configuration 3, the RMSE on $\mathrm{M}_{\mathrm{v}}$ estimates reaches 3.7 Vol.\% (RRMSE and MAPE about 14\%) for a noise on the modeled radar signal of \pm 0.75 (Table 9). Table 9 also shows that the RMSE on $M_{v}$ increases when the noise added to the modeled radar signal increases. This increase is approximately $1 \mathrm{Vol} \%$ when the noise on the radar signal increases from $\pm 0.75 \mathrm{~dB}$ to $\pm 1.00 \mathrm{~dB}$ (Table 9). Finally, Table 9 also shows that the three inversion configurations provide un-biased $\mathrm{M}_{\mathrm{v}}$ estimates and significant correlation coefficient ( $\mathrm{R}^{2}$ between 0.77 and 0.90$)$.

Table 9. Statistical indexes on $\mathrm{M}_{\mathrm{v}}$ estimates according to the three inversion configurations (RMSE (Vol.\%) | RRMSE (\%) | MAPE (\%) | bias (Vol.\%) | R²). Configuration 1 uses HH and NDVI, configuration 2 uses HV and NDVI, and configuration 3 uses $\mathrm{HH}, \mathrm{HV}$ and NDVI. Relative noise of the NDVI $=15 \%$.

calculated using all $M_{v}$ values. The results showed that the RMSE of $M_{v}$ estimates increases with NDVI for all inversion configurations. As an example, in configuration 3 (HH, HV and NDVI), 
582 the RMSE of soil moisture estimates increases from $3.0 \mathrm{Vol} \%$ for NDVI of 0.45 to 4.8 Vol.\%

583 for a NDVI of 0.9 for a noise condition on the radar signal of $\pm 0.75 \mathrm{~dB}$ (Figure $6 \mathrm{a}$ ). The results

584 showed that for a given NDVI value between 0.45 and 0.90 , the RMSE is in same order in

585 configurations 1 and 2 (configuration 1 is slightly better than configuration 2) (Figure 6). In

586 addition, results obtained with $\mathrm{HH}$ were worse than those obtained with $\mathrm{HH}$ and $\mathrm{HV}$.

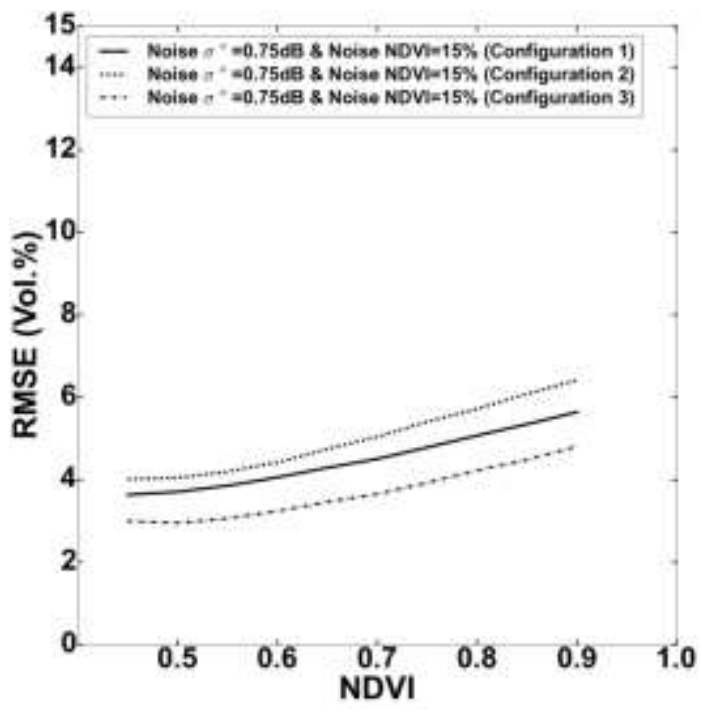

(a)

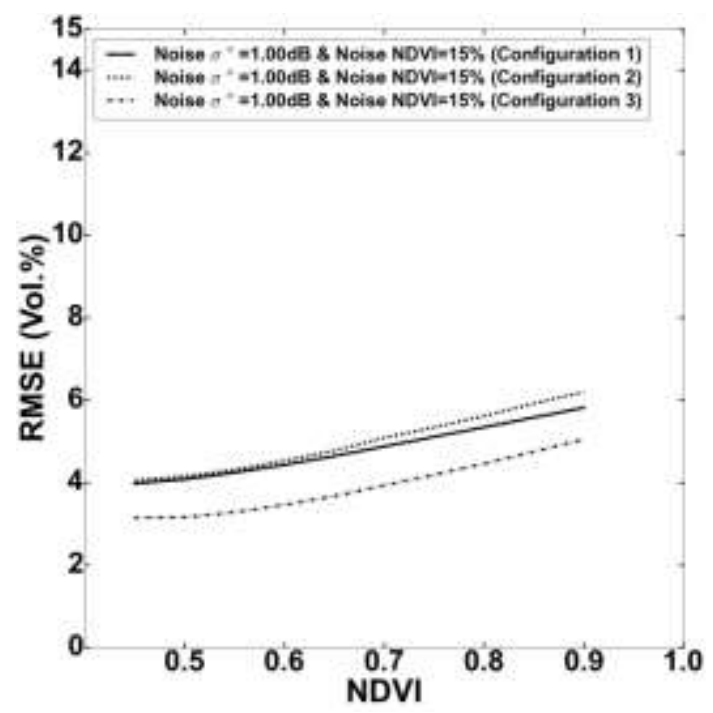

(b)

587 Figure 6. Evolution of RMSE of $\mathrm{M}_{\mathrm{v}}$ estimates according to the three inversion configurations as 588 a function of NDVI for noise conditions on the modeled radar signal of $\pm 0.75 \mathrm{~dB}(\mathrm{a})$, and $\pm 1 \mathrm{~dB}$ 589 (b).

Moreover, the performances of neural networks for estimating soil moisture were analyzed 591 according to NDVI for given $\mathrm{M}_{\mathrm{v}}$ values (Figure 7). The results showed that the relative RMSE 592 (RRMSE=RMSE/ $M_{v}$ ) of $M_{v}$ estimates increases with the NDVI for the three inversion 593 configurations. Indeed, as the vegetation grows (i.e., increasing NDVI values) the soil contribution decreases and the backscattering coefficients become less sensitive to soil moisture. 
595 In addition, for a given NDVI between 0.45 and 0.90 the RRMSE decreases when $\mathrm{M}_{\mathrm{v}}$ increases 596 (Figure 7) because for a given NDVI value the soil contribution is more important for high than 597 for low soil moisture conditions, and consequently, the errors on $M_{v}$ estimates decrease when $M_{v}$ 598 increases. As an example, in configuration 1 (HH and NDVI), for a NDVI of 0.75 (LAI about 3 $599 \mathrm{~m}^{2} / \mathrm{m}^{2}$ ), the RRMSE values are approximately $28.3,20.0,16.3$, and $12.0 \%$ for reference $\mathrm{M}_{\mathrm{v}}$ of $60015,20,30$ and 40 Vol.\%, respectively. For low $M_{v}$ (lower than 20 Vol.\%), the RRMSE increases 601 significantly with NDVI for high NDVI values (higher than 0.75 , LAI about $3 \mathrm{~m}^{2} / \mathrm{m}^{2}$ ) in 602 comparison to the RRMSE observed for higher $\mathrm{M}_{\mathrm{v}}$ values (higher than 20 Vol.\%). As an 603 example, in configuration 3 (HH, HV and NDVI), the RRMSE on $\mathrm{M}_{\mathrm{v}}$ estimates increases for $\mathrm{M}_{\mathrm{v}}$ 604 of $15 \mathrm{Vol} \%$ and noise condition on the simulated radar signal of $0.75 \mathrm{~dB}$ from approximately $60521 \%$ for $\mathrm{NDVI}=0.45$ to $30 \%$ for $\mathrm{NDVI}=0.90$. This increase in the RRMSE is only approximately $6065 \%$ for $M_{v}$ of 30 Vol. $\%$ (RRMSE increases from approximately $11 \%$ for NDVI=0.45 to $16 \%$ for 607 NDVI=0.90) (Figure 7). 


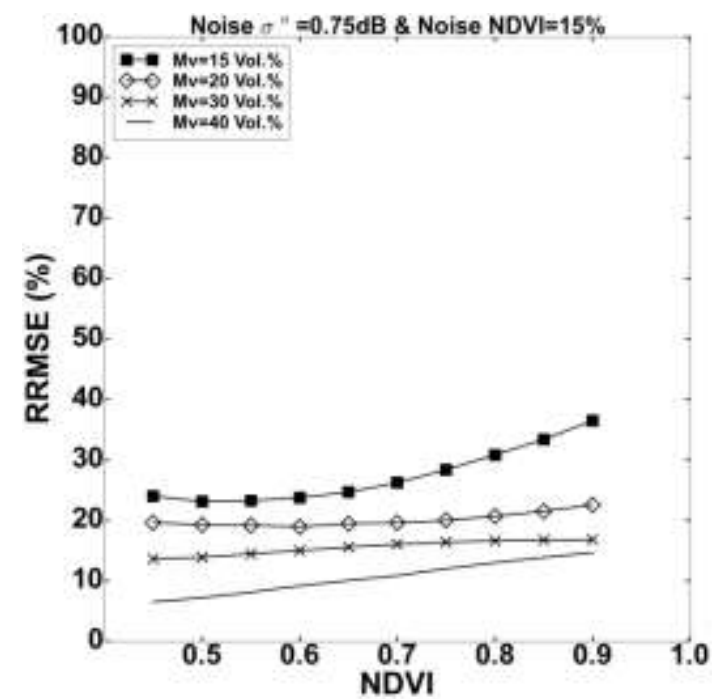

(a)

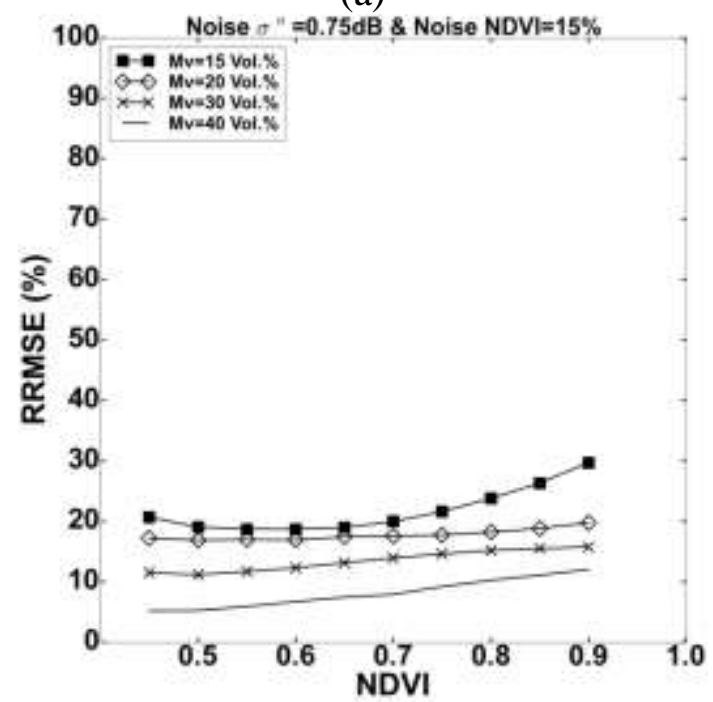

(c)

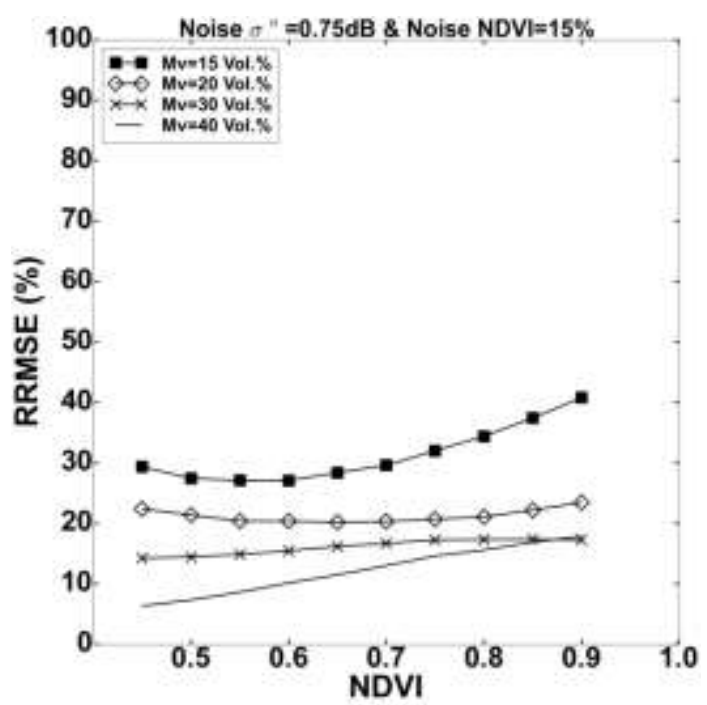

(b)

Figure 7. Evolution of the relative RMSE (in percent) of $M_{v}$ estimates (RRMSE=RMSE/ $M_{v}$ )

609 according to NDVI and $\mathrm{M}_{\mathrm{v}}$. (a) configuration 1: $\mathrm{HH}$ and NDVI, (b) configuration 2: HV and 610 NDVI, and (c) configuration 3: HH, HV and NDVI.

The difference between the estimated and reference $M_{v}$ were also analyzed as a function of 612 NDVI using for each NDVI and all $\mathrm{M}_{\mathrm{v}}$ values (Figure 8). For a given NDVI between 0.45 and 6130.90 , the bias on $M_{v}$ estimates is similar for radar signal noise of \pm 0.75 and $\pm 1 \mathrm{~dB}$. The results showed a slight underestimation (lower than approximately $1 \mathrm{Vol} . \%$ ) of $\mathrm{M}_{\mathrm{v}}$ estimates for NDVI 
615 values between $0.60\left(\mathrm{LAI}\right.$ about $\left.1 \mathrm{~m}^{2} / \mathrm{m}^{2}\right)$ and $0.90\left(\mathrm{LAI}\right.$ about $\left.6 \mathrm{~m}^{2} / \mathrm{m}^{2}\right)$. In addition, a slight 616 overestimation of $\mathrm{M}_{\mathrm{v}}$ is observed for a NDVI lower than 0.60 (lower than approximately 1 Vol. $\%)$.

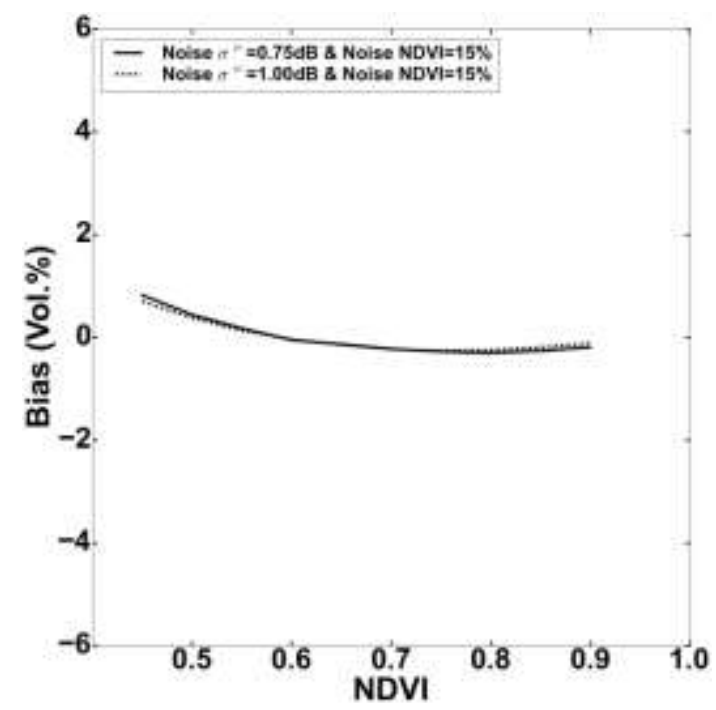

(a)

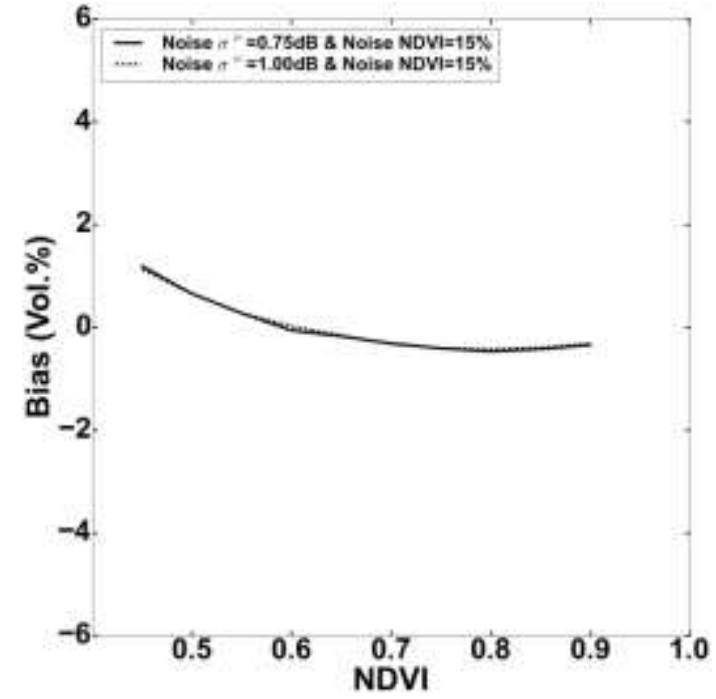

(c)

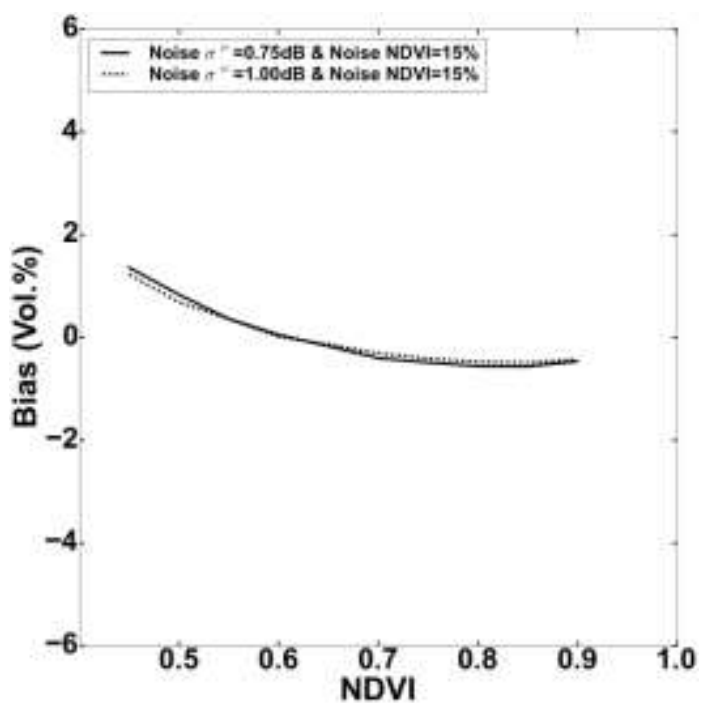

(b)

618 Figure 8. Evolution of the bias (estimated $M_{v}-$ reference $M_{v}$ ) of $M_{v}$ estimates according to

619 NDVI values. (a) Inversion configuration 1, (b) inversion configuration 2, and (c) inversion 620 configuration 3. 
Figure 9 shows the evolution of bias on $\mathrm{M}_{\mathrm{v}}$ estimates obtained for the three inversion 622 configurations as a function of the NDVI for some $\mathrm{M}_{\mathrm{v}}$ values (15, 20, 30 and 40 Vol.\%). For 623 NDVI values lower than approximately 0.65 (LAI about $1.5 \mathrm{~m}^{2} / \mathrm{m}^{2}$ ), the bias on $\mathrm{M}_{\mathrm{v}}$ estimates is 624 lower than $1.5 \mathrm{Vol} \%$ for $\mathrm{M}_{\mathrm{v}}$ between 15 and $40 \mathrm{Vol} \%$, in the case of configurations 1 and 3. For 625 the inversion configuration 2, the bias reaches $5.4 \mathrm{Vol} . \%$ (for $\mathrm{M}_{\mathrm{v}}=40 \mathrm{Vol} \%$ ). In addition, results 626 showed that the bias increased when the NDVI increased, regardless of the $\mathrm{M}_{\mathrm{v}}$ values. This 627 increase was mainly observed when the NDVI was greater than 0.75 (LAI about $3 \mathrm{~m}^{2} / \mathrm{m}^{2}$ ) for 628 low $M_{v}$ values (Figure 9). An overestimation of $M_{v}$ estimates is mainly observed for $M_{v}$ values 629 lower than $20 \mathrm{Vol} \%$, while an underestimation is mainly observed for $\mathrm{M}_{\mathrm{v}}$ values higher than 30 630 Vol.\%. Figure 9 also showed that for a given $\mathrm{M}_{\mathrm{v}}$, the bias is lower for configurations 1 and 3. 631 The bias reaches $3.5 \mathrm{Vol} \%$ for configurations 1 and 3 compared to $5 \mathrm{Vol} \%$ for configuration 2 632 for NDVI $=0.9$ and $\mathrm{M}_{\mathrm{v}}=15 \mathrm{Vol} \%$. Figure 10 shows an example of box plots calculated for the 633 inversion of configuration 3 and some NDVI values $(0.6,0.7,0.8$ and 0.9$)$. 


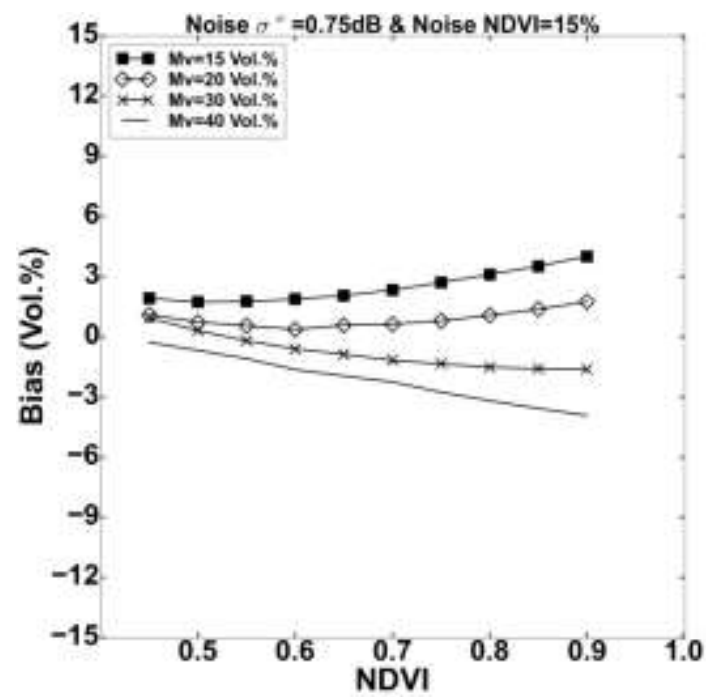

(a)

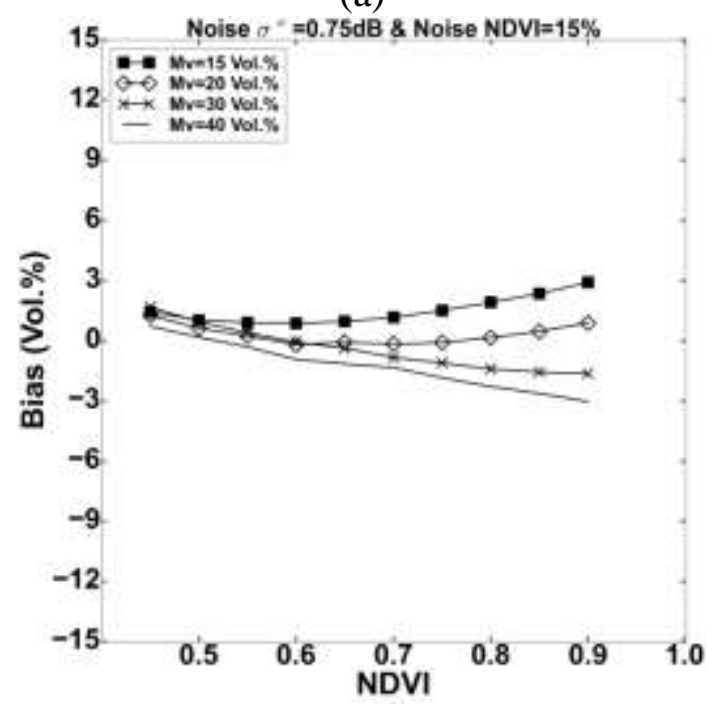

(c)

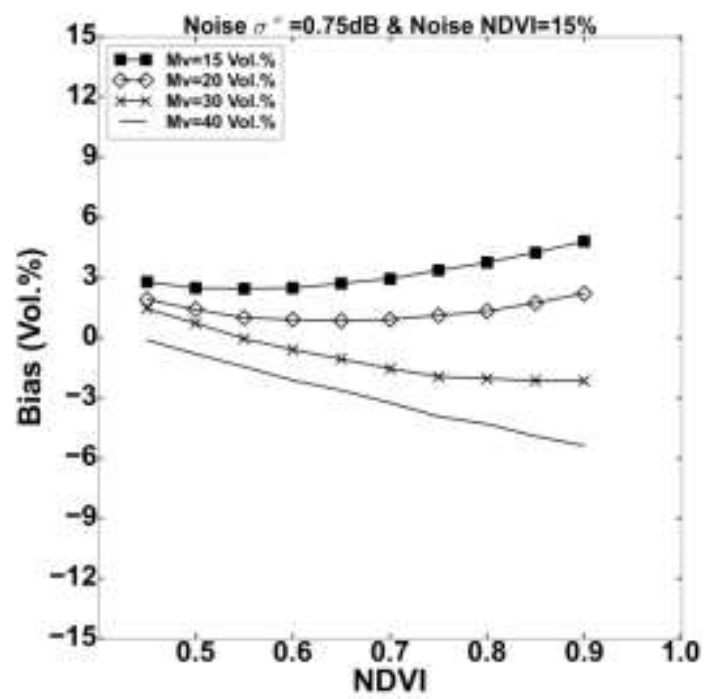

(b)

635 Figure 9. Evolution of the bias (estimated $M_{v}$ - reference $M_{v}$ ) on $M_{v}$ estimates according to

636 NDVI and $\mathrm{M}_{\mathrm{v}}$ values for noise on the modeled radar signal of $0.75 \mathrm{~dB}$. (a) configuration 1, (b)

637 configuration 2 , and (c) configuration 3. 

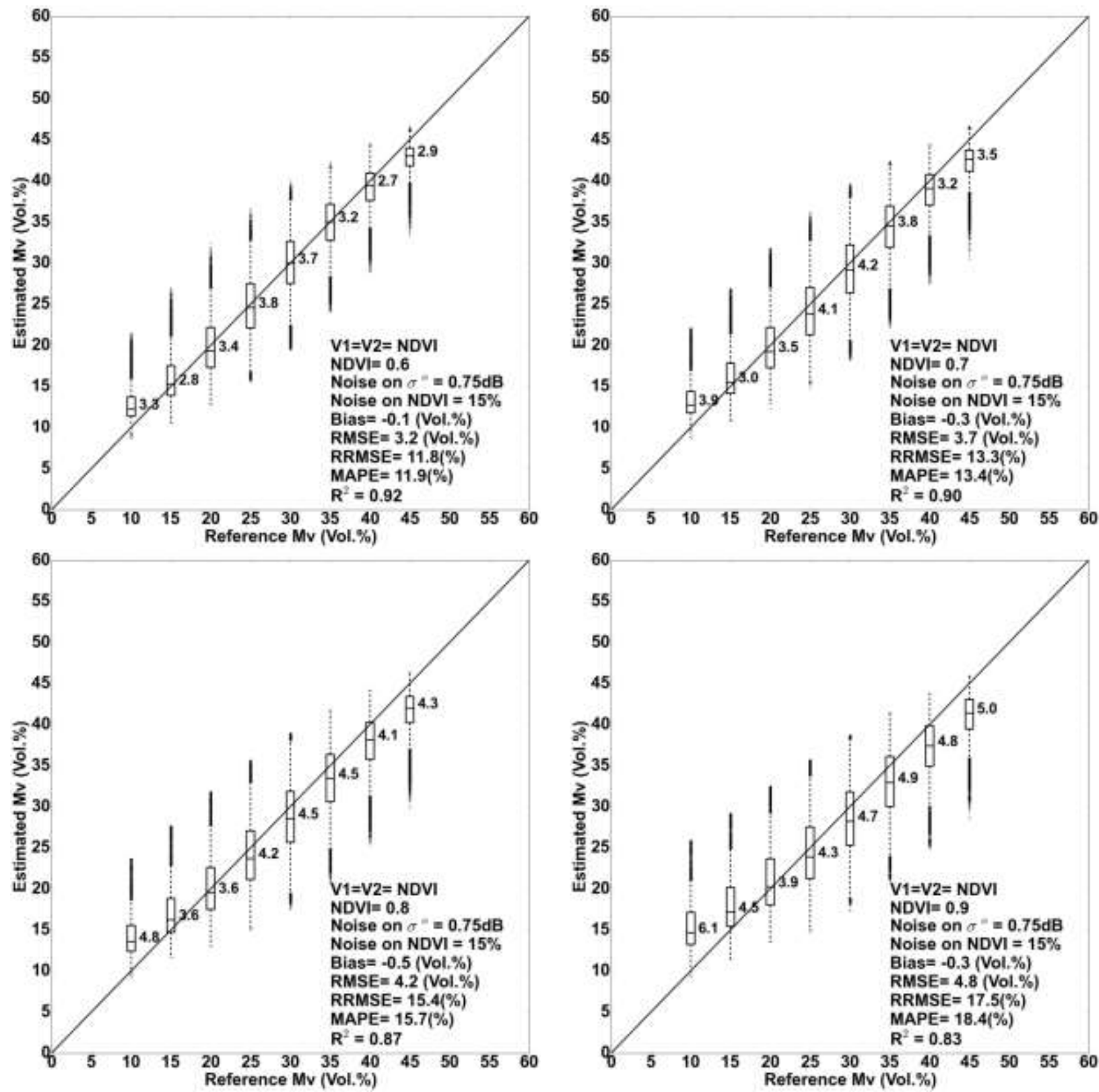

638 Figure 10. Box plots of $\mathrm{M}_{\mathrm{v}}$ estimates retrieved from the synthetic dataset. Neural networks were

639 trained and validated according to configuration 3 (using $\mathrm{HH}, \mathrm{HV}$ and NDVI). Noise on the

640 modeled radar signal is $\pm 0.75 \mathrm{~dB}$, and noise on NDVI is $15 \%$ of the NDVI value. Values to the

641 right of the box plots represent the RMSE on $M_{v}$ estimates for a given reference $M_{v}$. 
642 Moreover, 5-fold cross-validation was used to predict errors on $\mathrm{M}_{\mathrm{v}}$ estimates for each 643 inversion configuration performed using the synthetic dataset with LAI, FAPAR, and FCOVER 644 as vegetation descriptors. Table 10 shows statistics (RMSE, RRMSE, MAPE, bias, and $\mathrm{R}^{2}$ ) on $645 \mathrm{M}_{\mathrm{v}}$ estimates computed from the validation dataset for reference $\mathrm{M}_{\mathrm{v}}$ values between 10 and 45 646 Vol.\% and a LAI between 0 and 6 and FAPAR (as well as FCOER) between 0 and 1. The results 647 show that regardless of the vegetation descriptor used, the RMSE on $\mathrm{M}_{\mathrm{v}}$ estimates is lower using $648 \mathrm{HH}$ compared to HV polarization (configuration 1 in comparison to configuration 2). In addition, 649 the use of $\mathrm{HH}$ and $\mathrm{HV}$ polarizations slightly decreases the RMSE on $\mathrm{M}_{\mathrm{v}}$ estimates. Table 10 also 650 shows that the RMSE on $\mathrm{M}_{\mathrm{v}}$ estimates increases approximately $1 \mathrm{Vol} \%$ when noise added to the 651 radar signal increases. For each inversion configuration and for a given noise condition on the 652 modeled radar signal, the RMSE on $\mathrm{M}_{\mathrm{v}}$ estimates is in the same order with the use of NDVI, 653 LAI, FAPAR, or FCOVER as a vegetation descriptor (Table 10). Finally, the results showed that 654 whatever the vegetation descriptor used, the three inversion configurations provide un-biased $\mathbf{M}_{\mathrm{v}}$ 655 estimates. 
Table 10. RMSE and Bias on $\mathrm{M}_{\mathrm{v}}$ estimates according to the three inversion configurations (RMSE (Vol.\%) | RRMSE (\%) | MAPE (\%) | bias (Vol.\%) | $\mathrm{R}^{2}$ ). Configuration 1 uses HH and 658 vegetation descriptor, configuration 2 uses $\mathrm{HV}$ and vegetation descriptor, and configuration 3 659 uses HH, HV and vegetation descriptor.

\begin{tabular}{|c|c|c|}
\hline & $\begin{array}{c}\text { Noise on } \sigma_{\text {tot }}^{0}: \\
\quad \pm 0.75 \mathrm{~dB}\end{array}$ & $\begin{array}{c}\text { Noise on } \sigma_{\text {tot }}^{0}: \\
\quad \pm 1.00 \mathrm{~dB}\end{array}$ \\
\hline \multicolumn{3}{|l|}{$\mathrm{V} 1=\mathrm{V} 2=\mathrm{NDVI}$} \\
\hline \multicolumn{3}{|l|}{ Relative noise $=15 \%$} \\
\hline Configuration 1 & $4.5|16.5| 17.1|0.0| 0.85$ & $5.5|19.8| 21.0|0.0| 0.78$ \\
\hline Configuration 2 & $5.1|18.5| 19.2|0.0| 0.81$ & $5.7|20.7| 21.8|0.0| 0.77$ \\
\hline Configuration 3 & $3.7|13.6| 13.7|0.0| 0.90$ & $4.5|16.2| 16.7|0.0| 0.85$ \\
\hline \multicolumn{3}{|l|}{$\mathrm{V} 1=\mathrm{V} 2=\mathrm{LAI}$} \\
\hline \multicolumn{3}{|l|}{ Relative noise $=30 \%$} \\
\hline Configuration 1 & $5.6|20.5| 20.6|0.0| 0.76$ & $6.7|24.5| 25.4|0.0| 0.65$ \\
\hline Configuration 2 & $7.1|26.0| 26.9|0.0| 0.61$ & $8.1|29.3| 31.2|0.0| 0.50$ \\
\hline Configuration 3 & $5.2|0.0| 18.9|18.8| 0.79$ & $5.8|21.1| 21.3|0.0| 0.74$ \\
\hline \multicolumn{3}{|l|}{$\mathrm{V} 1=\mathrm{V} 2=\mathrm{FAPAR}$} \\
\hline \multicolumn{3}{|l|}{ Relative noise $=20 \%$} \\
\hline Configuration 1 & $5.2|18.9| 18.8|0.0| 0.79$ & $6.4|23.1| 24.1|0.0| 0.69$ \\
\hline Configuration 2 & $6.3|22.8| 23.3|0.0| 0.70$ & $7.3|26.7| 28.0|0.0| 0.59$ \\
\hline Configuration 3 & $4.4|16.0| 15.7|0.0| 0.85$ & $5.4|19.7| 19.9|0.0| 0.78$ \\
\hline \multicolumn{3}{|l|}{$\mathrm{V} 1=\mathrm{V} 2=\mathrm{FCOVER}$} \\
\hline \multicolumn{3}{|l|}{ Relative noise $=20 \%$} \\
\hline Configuration 1 & $5.2|18.7| 18.8|0.0| 0.80$ & $6.5|23.8| 24.4|0.0| 0.67$ \\
\hline Configuration 2 & $7.1|25.7| 26.7|0.0| 0.62$ & $7.8|28.3| 30.0|0.0| 0.54$ \\
\hline Configuration 3 & $4.7|16.9| 16.8|0.0| 0.84$ & $5.7|20.7| 20.9|0.0| 0.75$ \\
\hline
\end{tabular}


661 The capacity of the developed Neural Networks (NNs) to correctly estimate the soil moisture 662 was then tested using the real dataset. The NNs applied to the real validation dataset are those 663 which have been trained and validated using the synthetic dataset. NDVI, LAI, FAPAR and 664 FCOVER derived from optical images were used as the input vegetation descriptors for the 665 trained NNs. Inversion results obtained with the NDVI derived from optical images as the 666 vegetation descriptor will be provided in detail, whereas the results based on the LAI, FAPAR, 667 FCOVER derived from optical images as the vegetation descriptor will be briefly described.

668 First, statistics (RMSE, RRMSE, MAPE, bias, $\mathrm{R}^{2}$ ) on $\mathrm{M}_{\mathrm{v}}$ estimates were also computed for 669 all NDVI observations (Table 11). Slightly better statistics were observed with the noise on a 670 modeled radar signal of $\pm 1.00 \mathrm{~dB}$. With the noise of $\pm 1.00 \mathrm{~dB}$, the RMSE is $4.5,6.0$ and 5.5 671 Vol.\% in configuration 1, 2 and 3, respectively. Moreover, a slight underestimation (about -0.1 672 Vol.\%) was observed in configuration 1 for the noise conditions of $\pm 0.75 \mathrm{~dB}$ and $\pm 1.00 \mathrm{~dB}$. For 673 configurations 2 and 3, an underestimation of $M_{v}$ estimates was observed (about -1.4 Vol.\% in 674 configuration 2 and -1 Vol.\% in configuration 3 ). 
675 Table 11. statics on $\mathrm{M}_{\mathrm{v}}$ estimates according to the three inversion configurations (RMSE 676 (Vol.\%)| RRMSE (\%)| MAPE (\%) | bias Vol.\% | $\mathrm{R}^{2} \mid$ samples). Configuration 1 uses HH and 677 NDVI, configuration 2 uses $\mathrm{HV}$ and NDVI, and configuration 3 uses HH, HV and NDVI. 678 Relative noise on the NDVI=15\%. Real SAR measurements and the LAI derived from optical 679 images were used to estimate $\mathrm{M}_{\mathrm{v}}$.

\begin{tabular}{|c|c|c|}
\hline & Noise on $\sigma_{\text {tot }}^{0}: \pm 0.75 \mathrm{~dB}$ & Noise on $\sigma_{\text {tot }}^{0}: \pm 1.00 \mathrm{~dB}$ \\
\hline & $\mathrm{NDVI}=[0.45-0.90]$ & $\mathrm{NDVI}=[0.45-0.90]$ \\
\hline Configuration 1 (HH and NDVI) & $4.9|18.4| 16.4|-0.1| 0.60 \mid 93$ & $4.5|17.0| 15.5|-0.1| 0.63 \mid 93$ \\
\hline Configuration 2 (HV and NDVI) & $6.8|25.7| 23.1|-1.3| 0.37 \mid 93$ & $6.0|22.6| 19.8|-1.3| 0.42 \mid 93$ \\
\hline Configuration 3 (HH, HV and NDVI) & $6.2|23.5| 21.2|-0.8| 0.49 \mid 93$ & $5.5|20.5| 18.0|-0.9| 0.53 \mid 93$ \\
\hline
\end{tabular}

Next, the statistics were computed from the real dataset of validation for NDVI classes of 0.05

681

682

683

684

685

686

687

688

689

690

691

(NDVI was derived from optical images are between 0.45 and 0.9 ). The results showed that the

RMSE on $\mathrm{M}_{\mathrm{v}}$ estimates was in the same order for NDVI classes between 0.45 and 0.75 (LAI about $3 \mathrm{~m}^{2} / \mathrm{m}^{2}$ ) on the one hand (difference lower than $1 \mathrm{Vol} . \%$ ), and on the other hand for NDVI classes between $0.75\left(\mathrm{LAI}\right.$ about $3 \mathrm{~m}^{2} / \mathrm{m}^{2}$ ) and $0.90\left(\mathrm{LAI}\right.$ about $6 \mathrm{~m}^{2} / \mathrm{m}^{2}$ ). Therefore, the results of $\mathrm{M}_{\mathrm{v}}$ estimates were presented for two classes of NDVI: NDVI lower and higher than 0.75 (Table 12). The comparison between estimated $M_{v}$ and $M_{v}$ ground-truthed measurements is given in Figures 11 and 12. RMSE and bias on $\mathrm{M}_{\mathrm{v}}$ estimates are lower with the noise condition on the modeled radar signal of $\pm 1 \mathrm{~dB}$.

RMSE of 3.6 (RRMSE and MAPE about 12\%), 5.4 (RRMSE and MAPE about 18\%), and 4.4 (RRMSE and MAPE about 15\%) Vol.\% were observed for configurations 1, 2 and 3, respectively, in the case of a NDVI lower than 0.75 and for modeled radar signal noise of $\pm 1 \mathrm{~dB}$ 
692 (Table 12, Figure 11). For a NDVI higher than 0.75, the RMSE on $\mathrm{M}_{\mathrm{v}}$ estimates is 6.1 (RRMSE 693 and MAPE about 24\%), 7.1 (RRMSE and MAPE about 28\%) and 7.3 (RRMSE and MAPE 694 about 29\%) Vol.\%, respectively, for configurations 1, 2 and 3 and for the noise on the modeled 695 radar signal of $\pm 1 \mathrm{~dB}$ (Table 12, Figure 11). Moreover, results showed that for a NDVI $<0.75$ 696 the trained $\mathrm{NNs}$ provide $\mathrm{M}_{\mathrm{v}}$ estimates with slight bias (0.2, - 1.7 , and -0.9 Vol.\% in 697 configurations 1, 2 and 3, respectively) (Table 12, Figure 11). For a NDVI > 0.75, an slight bias 698 (between -1 and $0.1 \mathrm{Vol} . \%$ ) was observed for the noise on the radar signal of $\pm 1 \mathrm{~dB}$, with the 699 lower value for the inversion using HH and NDVI (0.1 Vol.\%) (Table 12, Figure 11).

Table 12. RMSE and bias on $M_{v}$ estimates according to the three inversion configurations (RMSE (Vol.\%) | RRMSE (\%) | MAPE (\%) | bias Vol.\% | $\mathrm{R}^{2} \mid$ samples). Configuration 1 uses $702 \mathrm{HH}$ and NDVI, configuration 2 uses $\mathrm{HV}$ and NDVI, and configuration 3 uses $\mathrm{HH}$, HV and 703 NDVI. Relative noise on the NDVI=15\%. Real SAR measurements and NDVI derived from optical images were used to estimate $\mathrm{M}_{\mathrm{v}}$.

\begin{tabular}{|c|c|c|c|c|}
\hline & \multicolumn{2}{|c|}{ Noise on $\sigma_{\text {tot }}^{0}: \pm 0.75 \mathrm{~dB}$} & \multicolumn{2}{|c|}{ Noise on $\sigma_{\text {tot }}^{0}: \pm 1.00 \mathrm{~dB}$} \\
\hline & NDVI $<0.75$ & NDVI $>0.75$ & NDVI $<0.75$ & $\mathrm{NDVI}>0.75$ \\
\hline \multirow{2}{*}{ Configuration 1} & $3.8|13.9| 12.4$ & $6.6|27.3| 25.3$ & $3.6|13.1| 11.8$ & $6.1|24.9| 23.5$ \\
\hline & $|0.0| 0.77 \mid 64$ & $|-0.3| 0.07 \mid 29$ & $|-0.2| 0.79 \mid 64$ & $|0.1| 0.10 \mid 29$ \\
\hline \multirow{2}{*}{ Configuration 2} & $6.0|21.7| 19.8$ & $8.4|34.5| 30.6 \mid$ & $|5.4| 19.7|17.0|$ & $7.1|29.2| 26.1$ \\
\hline & $|-1.5| 0.52 \mid 64$ & $-0.8|0.04| 29$ & $-1.7|0.56| 64$ & $|-0.5| 0.07 \mid 29$ \\
\hline \multirow[b]{2}{*}{ Configuration 3} & $5.0|18.2| 16.8$ & $8.3|34.2| 30.9$ & $4.4|15.8| 13.9$ & $7.3|30.1| 26.9$ \\
\hline & $|-0.7| 0.67 \mid 64$ & $|-1.1| 0.04 \mid 29$ & $|-0.9| 0.71 \mid 64$ & $|-1.0| 0.06 \mid 29$ \\
\hline
\end{tabular}

Moreover, the SAR real validation dataset was inverted to estimate soil moisture by means of 706 trained NNs with the use of each of the vegetation descriptors derived from optical images LAI, 
707 FAPAR, and FCOVER). Table 13 shows the (RMSE, RRMSE, MAPE, bias, $\mathrm{R}^{2}$ ) on $\mathrm{M}_{\mathrm{v}}$ 708 estimates in the three inversion configurations for two classes of NDVI: NDVI lower and higher 709 than $0.75\left(\mathrm{LAI}\right.$ about $3 \mathrm{~m}^{2} / \mathrm{m}^{2}$ ). The results showed that the RMSE (as well as RRMSE, MAPE) 710 on $\mathrm{M}_{\mathrm{v}}$ estimates are almost similar, regardless of which vegetation descriptors derived from 711 optical images were used (NDVI, LAI, FAPAR, or FCOVER) (Table 13).

712 In conclusion, the use of HH polarization in addition to a vegetation descriptor derived from 713 optical images (Configuration 1) provides a better estimation of the soil moisture with a RMSE 714 approximately 4.5 and 7.0 Vol.\% for a NDVI lower and higher than 0.75 (LAI about $3 \mathrm{~m}^{2} / \mathrm{m}^{2}$ ), 715 respectively. The use of $\mathrm{HV}$ in addition to $\mathrm{HH}$ slightly lowers the precision of $\mathrm{M}_{\mathrm{v}}$ estimates. 
717 Table 13. Statics on $\mathrm{M}_{\mathrm{v}}$ estimates according to the three inversion configurations (RMSE 718 (Vol.\%)|RRMSE (\%)|MAPE (\%) | bias Vol.\% $\left|\mathrm{R}^{2}\right|$ samples). Configuration 1 uses HH and 719 NDVI, configuration 2 uses HV and NDVI, and configuration 3 uses HH, HV and NDVI. Real 720 SAR measurements, and NDVI, LAI, FAPAR and FCOVER derived from optical images were 721 used to estimate $\mathrm{M}_{\mathrm{v}}$.

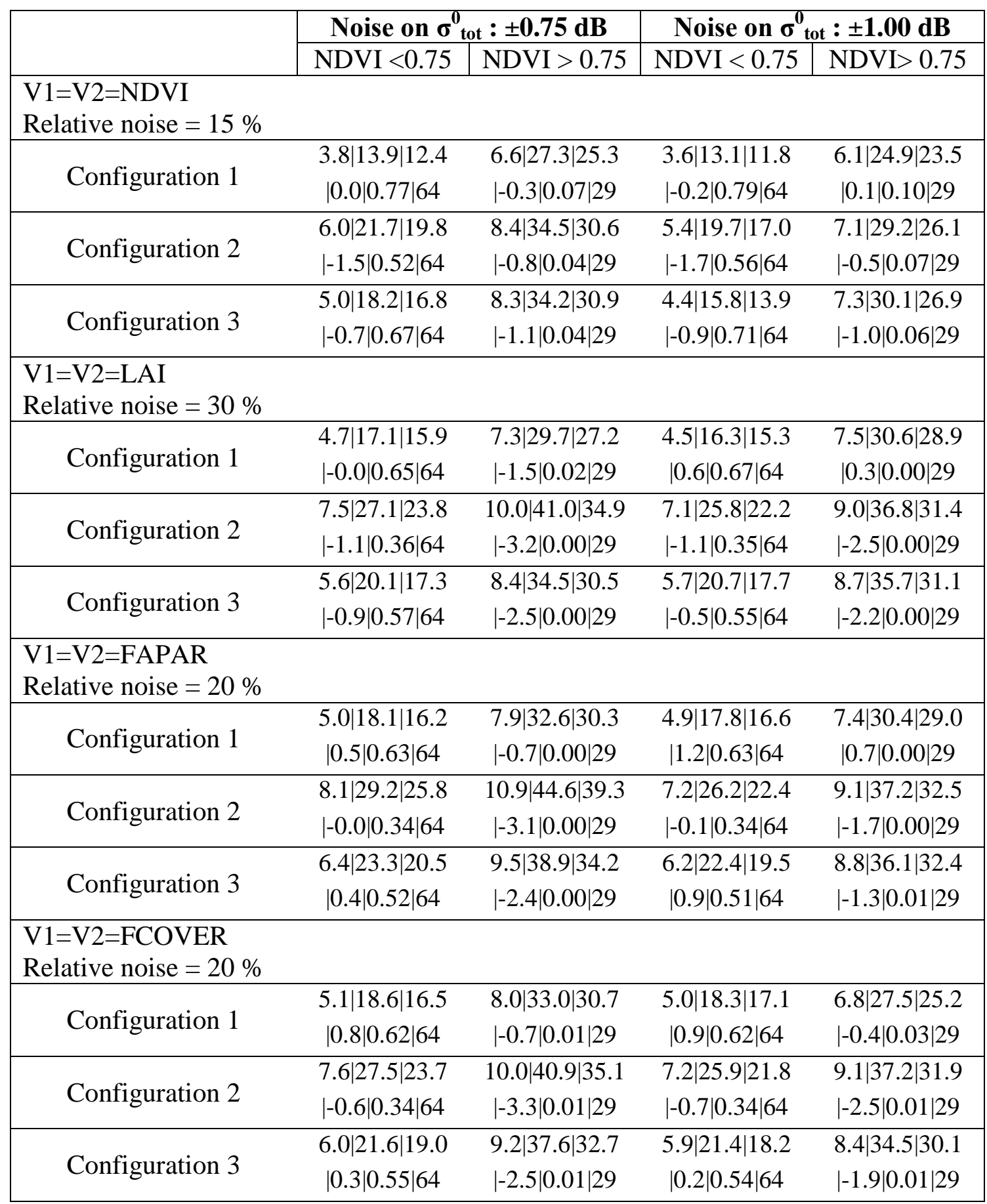




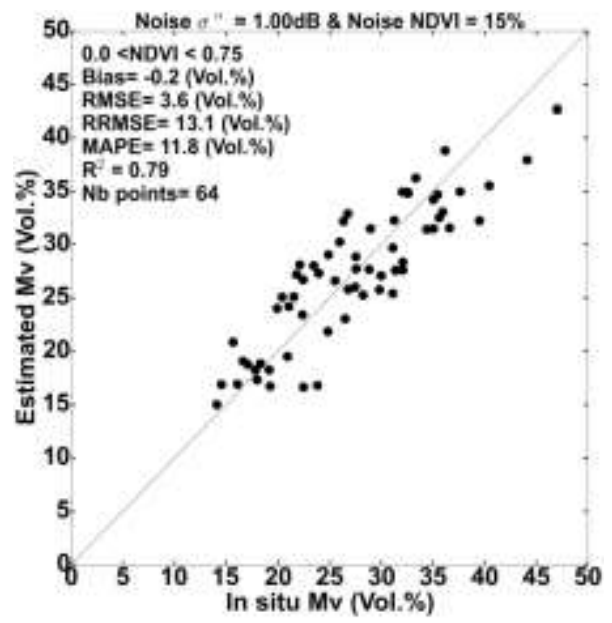

(a)

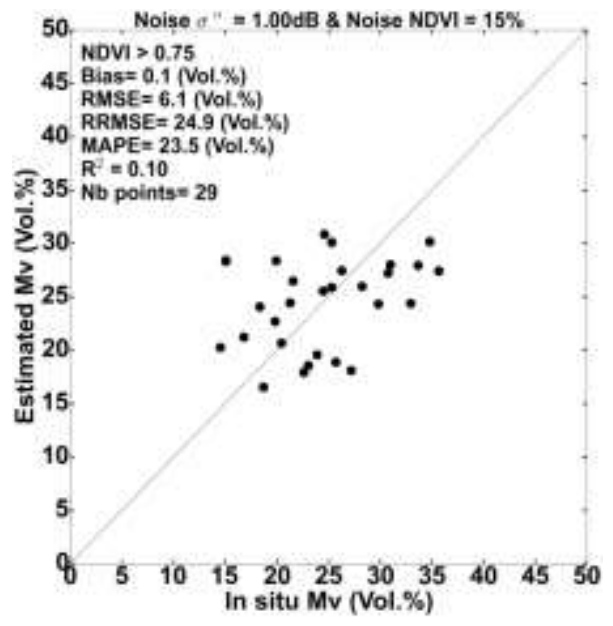

(b)
723

724

725

726

727

728

729

730

731

732

733

734

735

736

737

738

739

740

Figure 11. Retrieved soil moisture using configuration 1 versus ground-truthed measurements for NDVI lower and higher than 0.75 ( $a$, and $b$ respectively). Noise on radar signal $= \pm 1 \mathrm{~dB}$. Bias = estimated $\mathrm{M}_{\mathrm{v}}$ - reference $\mathrm{M}_{\mathrm{v}}$.

\section{Conclusion}

Inversion results of the synthetic dataset showed that the best $\mathrm{M}_{\mathrm{v}}$ estimates were obtained with the use of the X-band radar signal in $\mathrm{HH}$ polarization or in using both $\mathrm{HH}$ and $\mathrm{HV}$ polarizations, in addition to one vegetation descriptor derived from optical images. However, the use of $\mathrm{HV}$ in addition to one vegetation descriptor derived from optical images degrades the precision on $M_{v}$ estimates. Moreover, results showed that the RMSE on $M_{v}$ estimates is slightly sensitive to additive noise on the modelled radar signal. The RMSE increases approximately 1 Vol.\% when the noise of the radar signal increases from $\pm 0.75 \mathrm{~dB}$ to $\pm 1.00 \mathrm{~dB}$. For all NDVI values, the RMSE on $\mathrm{M}_{\mathrm{V}}$ estimates ( $\mathrm{M}_{\mathrm{v}}$ between 10 and $\left.45 \mathrm{Vol} . \%\right)$ was approximately 5.0 Vol.\% (RRMSE and MAPE about $19 \%$ ) in configurations 1 and 3. Similar values of the RMSE (as well as RRMSE and MAPE) on $\mathrm{M}_{\mathrm{v}}$ estimates were obtained with the use of LAI, FAPAR, and FCOVER as the vegetation descriptor. The accuracy of $\mathrm{M}_{\mathrm{v}}$ estimates degrades (i.e., an increase in the RMSE, RRMSE, and MAPE) with vegetation growth (i.e., an increase in the NDVI). As an example, in configuration 3 (HH, $\mathrm{HV}$ and NDVI), the RMSE on $\mathrm{M}_{\mathrm{v}}$ estimates increases from 
741

742

743

744

745

746

747

748

749

750

751

752

753

754

755

756

757

758

759

760

761

762

763

3.6 Vol.\% (RRMSE about 13\%) for NDVI of 0.45 to 5.7 Vol.\% (RRMSE about $21 \%$ ) for a NDVI of 0.9 .

From the real validation dataset (53\% of the real dataset), the soil moisture estimation using the X-band SAR data in addition to one vegetation descriptor derived from optical images allows better results with $\mathrm{HH}$ polarization than with $\mathrm{HV}$ or both $\mathrm{HH}$ and $\mathrm{HV}$. With $\mathrm{HH}$ and NDVI information derived from optical images, the accuracy on the soil moisture estimation was 3.6 Vol.\% (RRMSE and MAPE about 13\%) for NDVI between 0 and 0.75 (LAI about $3 \mathrm{~m}^{2} / \mathrm{m}^{2}$ ) and 6.1 Vol.\% (RRMSE and MAPE about 25\%) when the NDVI of the grassland was between 0.75 and 0.9 (LAI about $6 \mathrm{~m}^{2} / \mathrm{m}^{2}$ ). Similar results were obtained regardless the vegetation descriptor used.

With the arrival of new satellites, such as SENTINEL-1A (launched on 3 April 2014), in addition to future satellites SENTINEL-1B, SENTINEL-2A (optical sensor), and SENTINEL2B, it will be possible to obtain SAR (C-band) and optical remote sensing data covering global areas with high spatial and temporal resolutions (2 days with 2 SENTINEL-1 satellites, and 5 days for 2 SENTINEL-2 satellites at $10 \mathrm{~m}$ spatial resolution). Combining SENTINEL-1 data with optical images (SENTINEL-2, LANDSAT-7/8) will allow more precise estimation of $\mathrm{M}_{\mathrm{v}}$ because the radar signal penetration depth into vegetation cover is higher in the C-band compared to the X-band. This work is in the context of preparing for SENTINEL 1 and 2 missions.

This study demonstrated that the use of NNs technique to invert X-band SAR backscattering coefficients allows the estimation of soil moisture with acceptable accuracy (RMSE of 3.6 Vol.\% for a NDVI lower than 0.75). Current remote sensing sensors (optical and SAR) and those available in the near future (spatial resolution better than $10 \mathrm{~m}$ ) will allow the estimation of soil 
764 moisture at a field scale with high temporal resolution (better than weekly). Vegetation 765 biophysical parameters (i.e., LAI) and soil moisture that can be derived from optical and SAR 766 images could be useful to calibrate crop models for better irrigation management and crop 767 growth monitoring. Indeed, combining optical and SAR data would enhance the relevance of 768 remote sensing data for water and crop monitoring. 


\section{Acknowledgements}

770 This research was supported by the French Space Study Center (CNES, DAR 2014 TOSCA)

771 and the Islamic Development Bank (PhD Scholarship of M. Mohammad El Hajj). Field

772 experiments were carried out within the SicMed-Crau program. The CSK images used in this

773 analysis were supported by public funds received in the GEOSUD framework, a project (ANR-

774 10-EQPX-20) of the "Investissements d'Avenir" program managed by the French National

775 Research Agency. The authors wish to thank the German Space Agency (DLR) for kindly

776 providing the TSX images under proposal HYD0007. We also wish to thank the EMMAH unit

777 (INRA) for providing meteorological data and the technical teams of ASI and DLR for providing

778 answers regarding the performances of CSK and TSX. Finally, we would like to thank Olivier

779 Hagolle (CNES-CESBIO: Centre National d'Etudes Spatiales-Centre d'Etudes Spatiales de la 780 BIOsphère) for providing calibrated SPOT 4 images in the framework of Take 5 experiments. 
Agapiou, A., Hadjimitsis, D.G., Papoutsa, C., Alexakis, D.D., and Papadavid, G. (2011). The importance of accounting for atmospheric effects in the application of NDVI and interpretation of satellite imagery supporting archaeological research: the case studies of Palaepaphos and Nea Paphos sites in Cyprus. Remote Sens. 3, 2605-2629.

Agenzia Spaziale Italiana (2007). COSMO-SkyMed System Description \& User Guide.

Allen, R.G., Pereira, L.S., Raes, D., and Smith, M. (1998). Crop evapotranspiration-Guidelines for computing crop water requirements-FAO Irrigation and drainage paper 56. FAO Rome 300, 6541.

Attema, E.P.W., and Ulaby, F.T. (1978). Vegetation modeled as a water cloud. Radio Sci. 13, 357-364.

Aubert, M., Baghdadi, N., Zribi, M., Douaoui, A., Loumagne, C., Baup, F., El Hajj, M., and Garrigues, S. (2011). Analysis of TerraSAR-X data sensitivity to bare soil moisture, roughness, composition and soil crust. Remote Sens. Environ. 115, 1801-1810.

Baghdadi, N., Cresson, R., El Hajj, M., Ludwig, R., and La Jeunesse, I. (2012). Estimation of soil parameters over bare agriculture areas from C-band polarimetric SAR data using neural networks. Hydrol. Earth Syst. Sci. 16, 1607-1621.

Balenzano, A., Mattia, F., Satalino, G., and Davidson, M. (2011). Dense temporal series of Cand L-band SAR data for soil moisture retrieval over agricultural crops. Sel. Top. Appl. Earth Obs. Remote Sens. IEEE J. Of 4, 439-450.

Baret, F., and Guerif, M. (2006). Remote detection and quantification of plant stress: opportunities remote sensing observations. In Comparative Biochemistry and Physiology aMolecular \& Integrative Physiology, (ELSEVIER SCIENCE INC 360 PARK AVE SOUTH, NEW YORK, NY 10010-1710 USA), pp. S148-S148.

Baret, F., and Guyot, G. (1991). Potentials and limits of vegetation indices for LAI and APAR assessment. Remote Sens. Environ. 35, 161-173.

Baret, F., Hagolle, O., Geiger, B., Bicheron, P., Miras, B., Huc, M., Berthelot, B., Niño, F., Weiss, M., and Samain, O. (2007). LAI, fAPAR and fCover CYCLOPES global products derived from VEGETATION: Part 1: Principles of the algorithm. Remote Sens. Environ. 110, 275-286.

Botha, E.J., Leblon, B., Zebarth, B.J., and Watmough, J. (2010). Non-destructive estimation of wheat leaf chlorophyll content from hyperspectral measurements through analytical model inversion. Int. J. Remote Sens. 31, 1679-1697.

Bottraud, J.C., Bornand, M., and Servat, E. (1984). Mesures de résistivité appliquées à la cartographie en pédologie. Sci. Sol 4, 279-294. 
Brereton, A.J., and Hope-Cawdery, M. (1988). Drumlin soils: the depression of herbage yield by shallow water table depth. Ir. J. Agric. Res. 167-178.

Brown, S.C., Quegan, S., Morrison, K., Bennett, J.C., and Cookmartin, G. (2003). Highresolution measurements of scattering in wheat canopies-Implications for crop parameter retrieval. Geosci. Remote Sens. IEEE Trans. On 41, 1602-1610.

Bsaibes, A., Courault, D., Baret, F., Weiss, M., Olioso, A., Jacob, F., Hagolle, O., Marloie, O., Bertrand, N., and Desfond, V. (2009). Albedo and LAI estimates from FORMOSAT-2 data for crop monitoring. Remote Sens. Environ. 113, 716-729.

Carlson, T.N., and Ripley, D.A. (1997). On the relation between NDVI, fractional vegetation cover, and leaf area index. Remote Sens. Environ. 62, 241-252.

Carlson, T.N., Gillies, R.R., and Perry, E.M. (1994). A method to make use of thermal infrared temperature and NDVI measurements to infer surface soil water content and fractional vegetation cover. Remote Sens. Rev. 9, 161-173.

Ceccato, P., Flasse, S., Tarantola, S., Jacquemoud, S., and Grégoire, J.-M. (2001). Detecting vegetation leaf water content using reflectance in the optical domain. Remote Sens. Environ. 77, 22-33.

Chai, S.-S., Walker, J.P., Makarynskyy, O., Kuhn, M., Veenendaal, B., and West, G. (2009). Use of soil moisture variability in artificial neural network retrieval of soil moisture. Remote Sens. 2, $166-190$.

Champion, I. (1991). Etude et mise au point de modèles Semi-empiriques représentant la réponse de couverts végétaux dans le domaine hyperfréquence. Complémentarité avec le domaine optique. Thèse, Université Paris VII. France.

Champion, I., and Guyot, G. (1991). Generalized formulation for semi-empirical radar models representing crop backscattering. ESA Phys. Meas. Signat. Remote Sens. 1, 269-272.

Claverie, M., Vermote, E.F., Weiss, M., Baret, F., Hagolle, O., and Demarez, V. (2013). Validation of coarse spatial resolution LAI and FAPAR time series over cropland in southwest France. Remote Sens. Environ. 139, 216-230.

Coletta, A., Angino, G., Battazza, F., Caltagirone, F., Impagnatiello, F., Valentini, G., Capuzi, A., Fagioli, S., and Leonardi, R. (2007). COSMO-SkyMed program: Utilization and description of an advanced space EO dual-use asset. In Proc. Envisat Symp, pp. 23-27.

Courault, D., Bsaibes, A., Kpemlie, E., Hadria, R., Hagolle, O., Marloie, O., Hanocq, J.-F., Olioso, A., Bertrand, N., and Desfonds, V. (2008). Assessing the potentialities of FORMOSAT-2 data for water and crop monitoring at small regional scale in South-Eastern France. Sensors 8, 3460-3481.

Courault, D., Hadria, R., Ruget, F., Olioso, A., Duchemin, B., Hagolle, O., and Dedieu, G. (2010). Combined use of FORMOSAT-2 images with a crop model for biomass and water 
monitoring of permanent grassland in Mediterranean region. Hydrol. Earth Syst. Sci. Discuss. 7 , 1731-1744.

Darvishzadeh, R., Skidmore, A., Schlerf, M., and Atzberger, C. (2008a). Inversion of a radiative transfer model for estimating vegetation LAI and chlorophyll in a heterogeneous grassland. Remote Sens. Environ. 112, 2592-2604.

Darvishzadeh, R., Skidmore, A., Atzberger, C., and van Wieren, S. (2008b). Estimation of vegetation LAI from hyperspectral reflectance data: Effects of soil type and plant architecture. Int. J. Appl. Earth Obs. Geoinformation 10, 358-373.

Del Frate, F., and Solimini, D. (2004). On neural network algorithms for retrieving forest biomass from SAR data. Geosci. Remote Sens. IEEE Trans. On 42, 24-34.

Del Frate, F., Ferrazzoli, P., and Schiavon, G. (2003). Retrieving soil moisture and agricultural variables by microwave radiometry using neural networks. Remote Sens. Environ. 84, 174-183.

De Roo, R.D., Du, Y., Ulaby, F.T., and Dobson, M.C. (2001). A semi-empirical backscattering model at L-band and C-band for a soybean canopy with soil moisture inversion. Geosci. Remote Sens. IEEE Trans. On 39, 864-872.

Dubois, P.C., Van Zyl, J., and Engman, T. (1995). Measuring soil moisture with imaging radars. Geosci. Remote Sens. IEEE Trans. On 33, 915-926.

Duveiller, G., Weiss, M., Baret, F., and Defourny, P. (2011). Retrieving wheat Green Area Index during the growing season from optical time series measurements based on neural network radiative transfer inversion. Remote Sens. Environ. 115, 887-896.

Eineder, M., Fritz, T., Mittermayer, J., Roth, A., Boerner, E., and Breit, H. (2008). TerraSAR-X Ground Segment, Basic Product Specification Document. (Munich, Germany: DTIC Document, Cluster Applied Remote Sensing. Available online: https://tandemx-science.dlr.de/pdfs/TX-GSDD-3302_Basic-Products-Specification-Document_V1.6.pdf (accessed on 22 April 2011).).

El Hajj, M., Bégué, A., Lafrance, B., Hagolle, O., Dedieu, G., and Rumeau, M. (2008). Relative radiometric normalization and atmospheric correction of a SPOT 5 time series. Sensors 8, 27742791.

Fensholt, R., Sandholt, I., and Rasmussen, M.S. (2004). Evaluation of MODIS LAI, fAPAR and the relation between fAPAR and NDVI in a semi-arid environment using in situ measurements. Remote Sens. Environ. 91, 490-507.

Fieuzal, R., Duchemin, B., Jarlan, L., Zribi, M., Baup, F., Merlin, O., Hagolle, O., and GaratuzaPayan, J. (2011). Combined use of optical and radar satellite data for the monitoring of irrigation and soil moisture of wheat crops. Hydrol. Earth Syst. Sci. 15, 1117-1129.

Fung, A.K., Li, Z., and Chen, K.S. (1992). Backscattering from a randomly rough dielectric surface. Geosci. Remote Sens. IEEE Trans. On 30, 356-369. 
Gherboudj, I., Magagi, R., Berg, A.A., and Toth, B. (2011). Soil moisture retrieval over agricultural fields from multi-polarized and multi-angular RADARSAT-2 SAR data. Remote Sens. Environ. 115, 33-43.

Guerschman, J.P., Hill, M.J., Renzullo, L.J., Barrett, D.J., Marks, A.S., and Botha, E.J. (2009). Estimating fractional cover of photosynthetic vegetation, non-photosynthetic vegetation and bare soil in the Australian tropical savanna region upscaling the EO-1 Hyperion and MODIS sensors. Remote Sens. Environ. 113, 928-945.

Hagolle, O., Dedieu, G., Mougenot, B., Debaecker, V., Duchemin, B., and Meygret, A. (2008). Correction of aerosol effects on multi-temporal images acquired with constant viewing angles: Application to Formosat-2 images. Remote Sens. Environ. 112, 1689-1701.

He, B., Xing, M., and Bai, X. (2014). A Synergistic Methodology for Soil Moisture Estimation in an Alpine Prairie Using Radar and Optical Satellite Data. Remote Sens. 6, 10966-10985.

Hong, S., Malaterre, P.-O., Belaud, G., and Dejean, C. (2013). Optimization of water distribution for open-channel irrigation networks. Press J. Hydroinformatics.

Hosseini, M., and Saradjian, M.R. (2011). Soil moisture estimation based on integration of optical and SAR images. Can. J. Remote Sens. 37, 112-121.

Iorio, M., Mecozzi, R., and Torre, A. (2010). Cosmo SkyMed: antenna elevation pattern data evaluation. Ital. J Remote Sens 42, 69-77.

Leenhardt, D., Trouvat, J.-L., Gonzalès, G., Pérarnaud, V., Prats, S., and Bergez, J.-E. (2004). Estimating irrigation demand for water management on a regional scale: I. ADEAUMIS, a simulation platform based on bio-decisional modelling and spatial information. Agric. Water Manag. 68, 207-232.

Li, F., Chen, W., Zeng, Y., Zhao, Q., and Wu, B. (2014). Improving Estimates of Grassland Fractional Vegetation Cover Based on a Pixel Dichotomy Model: A Case Study in Inner Mongolia, China. Remote Sens. 6, 4705-4722.

Marquardt, D.W. (1963). An algorithm for least-squares estimation of nonlinear parameters. J. Soc. Ind. Appl. Math. 11, 431-441.

Masek, J.G., Vermote, E.F., Saleous, N., Wolfe, R., Hall, F.G., Huemmrich, F., Gao, F., Kutler, J., and Lim, T.K. (2013). LEDAPS calibration, reflectance, atmospheric correction preprocessing code, version 2. Model Prod.

Mattia, F., Le Toan, T., Picard, G., Posa, F.I., D’Alessio, A., Notarnicola, C., Gatti, A.M., Rinaldi, M., Satalino, G., and Pasquariello, G. (2003). Multitemporal C-band radar measurements on wheat fields. Geosci. Remote Sens. IEEE Trans. On 41, 1551-1560.

Mérot, A. (2007). Analyse et modélisation du fonctionnement biophysique et décisionnel d'un système prairial irrigué-Application aux prairies plurispécifiques de Crau en vue de l'élaboration 
d'un Outil d'Aide à la Décision. Thèse, Ecole nationale superieure agronomique de montpellierAGRO M. France.

Merot, A., Wery, J., Isberie, C., and Charron, F. (2008). Response of a plurispecific permanent grassland to border irrigation regulated by tensiometers. Eur. J. Agron. 28, 8-18.

North, P.R. (2002). Estimation of FAPAR, LAI, and vegetation fractional cover from ATSR-2 imagery. Remote Sens. Environ. 80, 114-121.

Notarnicola, C., Angiulli, M., and Posa, F. (2006). Use of radar and optical remotely sensed data for soil moisture retrieval over vegetated areas. Geosci. Remote Sens. IEEE Trans. On 44, 925935.

Oh, Y. (2004). Quantitative retrieval of soil moisture content and surface roughness from multipolarized radar observations of bare soil surfaces. Geosci. Remote Sens. IEEE Trans. On $42,596-601$.

Paloscia, S., Pampaloni, P., Pettinato, S., and Santi, E. (2008). A comparison of algorithms for retrieving soil moisture from ENVISAT/ASAR images. Geosci. Remote Sens. IEEE Trans. On 46, 3274-3284.

Paloscia, S., Pettinato, S., Santi, E., Notarnicola, C., Pasolli, L., and Reppucci, A. (2013). Soil moisture mapping using Sentinel-1 images: Algorithm and preliminary validation. Remote Sens. Environ. 134, 234-248.

Patel, P., and Srivastava, H.S. (2013). Ground truth planning for synthetic aperture radar (SAR): addressing various challenges using statistical approach. Int. J. Adv. Remote Sens. GIS Geogr. 1, $1-17$.

Peake, W.H. (1959). Interaction of electromagnetic waves with some natural surfaces. Antennas Propag. IRE Trans. On 7, 324-329.

Prakash, R., Singh, D., and Pathak, N.P. (2012). A fusion approach to retrieve soil moisture with SAR and optical data. Sel. Top. Appl. Earth Obs. Remote Sens. IEEE J. Of 5, 196-206.

Prévot, L., Champion, I., and Guyot, G. (1993). Estimating surface soil moisture and leaf area index of a wheat canopy using a dual-frequency ( $\mathrm{C}$ and $\mathrm{X}$ bands) scatterometer. Remote Sens. Environ. 46, 331-339.

Rahman, H., and Dedieu, G. (1994). SMAC: a simplified method for the atmospheric correction of satellite measurements in the solar spectrum. Int. J. Remote Sens. 15, 123-143.

Saastamoinen, J. (1972). Atmospheric correction for the troposphere and stratosphere in radio ranging satellites. Use Artif. Satell. Geod. 247-251.

Said, S., Kothyari, U.C., and Arora, M.K. (2012). Vegetation effects on soil moisture estimation from ERS-2 SAR images. Hydrol. Sci. J. 57, 517-534. 
Santi, E., Paloscia, S., Pettinato, S., Notarnicola, C., Pasolli, L., and Pistocchi, A. (2013). Comparison between SAR soil moisture estimates and hydrological model simulations over the Scrivia test site. Remote Sens. 5, 4961-4976.

Schwerdt, M., Bräutigam, B., Bachmann, M., and Döring, B. (2008). TerraSAR-X calibration results. In Synthetic Aperture Radar (EUSAR), 2008 7th European Conference on, (GrafZeppelin-Haus, Friedrichshafen, Germany: VDE), pp. 1-4.

Sikdar, M., and Cumming, I. (2004). A modified empirical model for soil moisture estimation in vegetated areas using SAR data. In Geoscience and Remote Sensing Symposium, 2004. IGARSS'04. Proceedings. 2004 IEEE International, (Anchorage, AK: IEEE), pp. 803-806.

Simoniello, T., Cuomo, V., Lanfredi, M., Lasaponara, R., and Macchiato, M. (2004). On the relevance of accurate correction and validation procedures in the analysis of AVHRR-NDVI time series for long-term monitoring. J. Geophys. Res. Atmospheres 1984-2012 109.

Soon-Koo Kweon, Ji-Hwan Hwang, and Yisok Oh (2012). COSMO SkyMed AO projects -soil moisture detection for vegetation fields based on a modified water-cloud model using COSMOSkyMed SAR data. Geosci. Remote Sens. Symp. IGARSS Munich Ger. 2012 IEEE Int. 12041207.

Srivastava, H.S., Patel, P., Manchanda, M.L., and Adiga, S. (2003). Use of multiincidence angle RADARSAT-1 SAR data to incorporate the effect of surface roughness in soil moisture estimation. IEEE Trans. Geosci. Remote Sens. 41, 1638-1640.

Srivastava, H.S., Patel, P., Sharma, Y., and Navalgund, R.R. (2009). Large-area soil moisture estimation using multi-incidence-angle RADARSAT-1 SAR data. Geosci. Remote Sens. IEEE Trans. On 47, 2528-2535.

Srivastava, H.S., Patel, P., Sharma, K.P., Krishnamurthy, Y.V.N., and Dadhwal, V.K. (2011). A semi-empirical modelling approach to calculate two-way attenuation in radar backscatter from soil due to crop cover. Curr. Sci. 100, 1871-1874.

Torre, A., Calabrese, D., and Porfilio, M. (2011). COSMO-SkyMed: Image quality achievements. In Recent Advances in Space Technologies (RAST), 2011 5th International Conference on, (Istanbul, Turkey: IEEE), pp. 861-864.

Ulaby, F.T., Allen, C.T., Eger Iii, G., and Kanemasu, E. (1984). Relating the microwave backscattering coefficient to leaf area index. Remote Sens. Environ. 14, 113-133.

Ulaby, F.T., Moore, R.K., and Fung, A.K. (1986). Microwave Remote Sensing: Active and Passive, vol. III, Volume Scattering and Emission Theory, Advanced Systems and Applications. Inc Dedham Mass. USA Norwood Mass. Artech House 1797-1848.

Vermote, E.F., El Saleous, N.Z., and Justice, C.O. (2002). Atmospheric correction of MODIS data in the visible to middle infrared: first results. Remote Sens. Environ. 83, 97-111. 
992 Wang, S.G., Li, X., Han, X.J., and Jin, R. (2011). Estimation of surface soil moisture and 993 roughness from multi-angular ASAR imagery in the Watershed Allied Telemetry Experimental 994 Research (WATER). Hydrol. Earth Syst. Sci. 15, 1415-1426.

995 Yang, G., Shi, Y., Zhao, C., and Wang, J. (2012). Estimation of soil moisture from multi996 polarized SAR data over wheat coverage areas. In Agro-Geoinformatics (Agro-Geoinformatics), 9972012 First International Conference on, (Shanghai, China: IEEE), pp. 1-5.

998 Yu, F., and Zhao, Y. (2011). A new semi-empirical model for soil moisture content retrieval by 999 ASAR and TM data in vegetation-covered areas. Sci. China Earth Sci. 54, 1955-1964.

1000 Zribi, M., Baghdadi, N., Holah, N., and Fafin, O. (2005). New methodology for soil surface 1001 moisture estimation and its application to ENVISAT-ASAR multi-incidence data inversion. 1002 Remote Sens. Environ. 96, 485-496.

1003 Zribi, M., Chahbi, A., Shabou, M., Lili-Chabaane, Z., Duchemin, B., Baghdadi, N., Amri, R., 1004 and Chehbouni, A. (2011). Soil surface moisture estimation over a semi-arid region using 1005 ENVISAT ASAR radar data for soil evaporation evaluation. Hydrol. Earth Syst. Sci. 15. 


\section{List of figures:}

1009 Figure 1. Location of the study site (Domaine du Merle). Black polygons delineate training

Figure 2. Ground-based photographs of study sites illustrating variations in grass growth stages

Figure 3. Sensitivity of radar signal in both $\mathrm{HH}$ and $\mathrm{HV}$ polarization to volumetric soil moisture.

Figure 4. Behavior of WCM components $\left(\sigma^{\circ}{ }_{\text {veg }}, \mathrm{T}^{2} \sigma^{\circ}{ }_{\text {sol }}\right.$, and $\left.\sigma^{\circ}{ }_{\text {tot }}\right)$ in both $\mathrm{HH}$ and $\mathrm{HV}$ polarizations according to $\mathrm{M}_{\mathrm{v}}$. Black points represent the SAR data ( $\sigma^{\circ}$ tot: real validation dataset) associated with NDVI measurements within \pm 0.1 of the NDVI used in the modelling.

Figure 5. Behavior of WCM components $\left(\sigma^{\circ}{ }_{\text {veg, }} \mathrm{T}^{2} \sigma^{\circ}\right.$ sol, and $\sigma^{\circ}$ tot $)$ in both $\mathrm{HH}$ and $\mathrm{HV}$ polarizations according to NDVI. Black points represent the SAR data $\left(\sigma^{\circ}{ }_{\text {tot }}\right.$ : real validation dataset) associated with $\mathrm{M}_{\mathrm{v}}$ measurements within \pm 5 vol. $\%$ of the $\mathrm{M}_{\mathrm{v}}$ used in the modelling. . 30

Figure 6. Evolution of RMSE of $\mathrm{M}_{\mathrm{v}}$ estimates according to the three inversion configurations as a function of NDVI for noise conditions on the modeled radar signal of $\pm 0.75 \mathrm{~dB}$ (a), and $\pm 1 \mathrm{~dB}$ (b).

Figure 7. Evolution of the relative RMSE (in percent) of $M_{v}$ estimates (RRMSE=RMSE/ $M_{v}$ ) according to NDVI and $\mathrm{M}_{\mathrm{v}}$. (a) configuration 1: HH and NDVI, (b) configuration 2: HV and

1027 Figure 8. Evolution of the bias (estimated $M_{v}$ - reference $M_{v}$ ) of $M_{v}$ estimates according to NDVI values. (a) Inversion configuration 1, (b) inversion configuration 2, and (c) inversion configuration 3 .

Figure 9. Evolution of the bias (estimated $M_{v}$ - reference $M_{v}$ ) on $M_{v}$ estimates according to NDVI and $M_{v}$ values for noise on the modeled radar signal of $0.75 \mathrm{~dB}$. (a) configuration 1, (b) configuration 2 , and (c) configuration 3.

Figure 10. Box plots of $\mathrm{M}_{\mathrm{v}}$ estimates retrieved from the synthetic dataset. Neural networks were trained and validated according to configuration 3 (using $\mathrm{HH}, \mathrm{HV}$ and NDVI). Noise on the modeled radar signal is $\pm 0.75 \mathrm{~dB}$, and noise on NDVI is $15 \%$ of the NDVI value. Values to the

Figure 11. Retrieved soil moisture using configuration 1 versus ground-truthed measurements for NDVI lower and higher than 0.75 ( $\mathrm{a}$, and $\mathrm{b}$ respectively). Noise on radar signal $= \pm 1 \mathrm{~dB}$. Bias $=$ estimated $M_{v}$ - reference $M_{v}$. 